MLM-1831

\section{DR-1891}

MLM-1831

\title{
Examination of SNAP-27 \\ Heat Source FCA4 and \\ Preparation of Fuel for FCA8
}

\author{
D. L. Prosser
}

July 23,1971

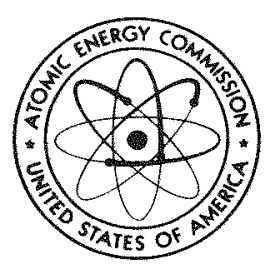

AEC Research and Development Report

\section{MOUND LABORATORY}

Miamisburg, Ohio

operated by

Monsanto

MONSANTO RESEARCH CORPORATION

a subsidiary of Monsanto Company

for the

U. S. ATOMIC ENERGY COMMISSION

U. S. Government Contract No. AT-33-1-GEN-53 


\section{DISCLAIMER}

This report was prepared as an account of work sponsored by an agency of the United States Government. Neither the United States Government nor any agency Thereof, nor any of their employees, makes any warranty, express or implied, or assumes any legal liability or responsibility for the accuracy, completeness, or usefulness of any information, apparatus, product, or process disclosed, or represents that its use would not infringe privately owned rights. Reference herein to any specific commercial product, process, or service by trade name, trademark, manufacturer, or otherwise does not necessarily constitute or imply its endorsement, recommendation, or favoring by the United States Government or any agency thereof. The views and opinions of authors expressed herein do not necessarily state or reflect those of the United States Government or any agency thereof. 


\section{DISCLAIMER}

Portions of this document may be illegible in electronic image products. Images are produced from the best available original document. 


\section{Examination of SNAP-27 Heat Source FCA4 and Preparation of Fuel for FCA8}

\author{
D. L. Prosser \\ Issued: July 23, 1971
}

This report was prepared as an account of work sponsored by the United States Government. Neither the United States nor the Untited States Atomic Energy Commission, nor any of their employees, nor any of theit contractors, subcontractors, or their employees, makes any warranty, express or implied, or assumes any legal liability or responsibility for the accuracy, completeness or usefulness of any information, apparatus, pleteness or usefulness of any information, apparatus,
product or process disclosed, or represents that its use would not infringe privately owned rights.

\section{LEGAL NOT/CE}

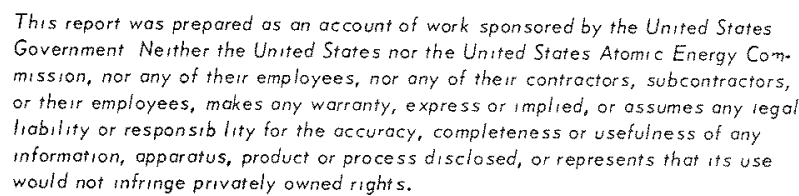

PRINTEDIN THE UNITED STATES OF AMERICA

$$
\text { Avallable from }
$$

Nattonal Techncal Intormatson Service

U S Department of Commerce

5285 Port Royal Road

Springfield, Virgina 2215

Price Printed Copy $\$ 3.00$, Microfiche $\$ 095$

\section{MONSANTO RESEARCH CORPORATION}

A Subsidiary of Monsanto Company

\section{MOUND LABORATORY}

Miamisburg, Ohio

45342

operated for

\section{UNITED STATES ATOMIC ENERGY COMMISSION}

US Government Contract No AT-33-1-GEN-53 
TABLE OF CONTENTS

\section{Page}

Abstract . . . . . . . . . . . . . . . . . . 3

Introduction . . . . . . . . . . . . . . . . . . 4

Experimental

Capsule Evaluation . . . . . . . . . . . . . . . 5

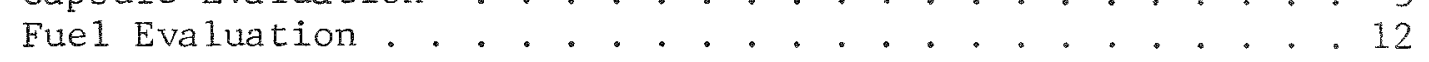

Acknowledgements . . . . . . . . . . . . . . . . . 49 


\section{ABSTRACT}

The capsule and fuel of SNAP- 27 fuel capsule assembly (FCA) 4 were examined for changes which may have occurred during its life of 2.25 yr. No significant effects were noted. The fuel was reprocessed and qualified for use in SNAP-27 FCA8. 


\section{INTRODUCTION}

In early 1970 the U. S. Atomic Energy Commission authorized the fabrication of a SNAP-27 heat source for the Apollo 17 lunar mission. To provide the fuel for the source the plutonium-238 dioxide microsphere fuel was to be removed from the fuel capsule assembly (FCA) 4 which had been made in May 1968 for qualification test purposes. Because FCA4 had been subjected to a more stringent vibration and shock testing program than the flight capsules and had seen an extensive and varied thermal environment, it was considered important to examine the fuel and capsule in detail to determine the effects of the physical and thermal exposures on them and to evaluate the suitability of the fuel for use in the new capsule.

The results of the examination would indicate the condition of the flight units. These units had not experienced as severe a physical or thermal regime as FCA4 and should be in at least as good condition as FCA4. The tests which were performed on the capsule assembly were:

\section{Capsule Evaluation}

1. Visual examination

2. Dimensional test

3. Leak test

4. Radiographic examination

5. Metallurgic examination

II. Fuel Evaluation

1. Dose rate measurements

2. Helium retention studies

3. Fuel fines determination

4. Helium removal studies

Following the test program, which began in July 1970, the fuel was baked out to remove the helium. The fuel then was processed and sealed into 
the capsule in accordance with the SNAP-27 heat source specification MD1-11391.

\section{EXPERIMENTAL}

\section{Capsule Evaluation}

1. Visual Examination - The capsule was inspected primarily to determine the condition of the emissive coating on its surface. The unit was supported vertically in a holder and the coating was examined along the length of the capsule and at several locations around its circumference. A Questar telescope was used to study the coating. The coating was found to have only a few minor defects and appeared to be in good condition considering the thermal cycling and mechanical stresses ${ }^{1}$ to which the capsule had been subjected.

2. Dimensional Test - The capsule was placed in the final assembly gage in air and passed both the straightness test for the bottom of the capsule and the closure weld diameter test. Any loss of straightness or increase in diameter was minimal, as the capsule was still within specification. On length it was found that the leaf gage at the bottom of the gage assembly would not pass completely under the capsule. It was estimated that the increase in length was of the order of a few thousandths of an inch. Because the capsule was coated, the assembly gage used at the General Electric Vallecitos plant was obtained for the test.

3. Leak Test - A helium leak test was performed to determine the integrity of the capsule and the welds. The leak rate was found to be $9.7 \times 10^{-}$std $\mathrm{cc}$ helium/sec, 26 months after manufacture. The value at time of fabrication was $1.0 \times 10^{-1} \mathrm{std} \mathrm{cc}$ helium/sec. The accuracy of the measurements was $+20 \%$.

4. Kadiographic Examination - The clad closure welds were examined by tangential radiography. The welds were found to be free of defects as they were at the time of fabrication.

5. Metallurgic Examination - One-inch-square sections of the walls from both fueled liners along with a section from an unfueled liner were sent to the Los Alamos Scientific Laboratory (LASL) for metallographic analysis. The study was performed to determine whether any reaction had occurred between the Iiner material (Haynes alloy No. 25) and the

SNAP-27 Summary Report DIN, GEMS402, General Electric Compary (July 15, 1970), pp. 6-13. 
fue1. The sections were given the following designations:

$$
\begin{aligned}
& \text { IA - Outer tube of fueled liner A } \\
& \text { IB - Inner tube of fueled liner A } \\
& 2 A \text { - Outer tube of fueled liner B } \\
& 2 B \text { - Inner tube of fueled liner B } \\
& 3 A \text { - Outer tube of empty liner }
\end{aligned}
$$

The outer tube sections included a portion of the circumferential weld used to join the bottom cap to the outer tube. One of the inner tube sections, $2 \mathrm{~B}$, contained a portion of the seam weld used in forming the tubing. The approximate locations of the sections taken from the liners are shown in Figure 1.

The sections were mounted and polished at LASL and etched electrolytically in a solution of four parts $\mathrm{HCl}$, one part $\mathrm{HNO}_{3}$, one part $\mathrm{HAc}$, and one part $\mathrm{H}_{2} \mathrm{O}$ at a voltage of $1.5 \mathrm{~V}$ for $1-2$ sec.

Preliminary photographs of the sections taken at LASL are shown in the following figures. All views were taken at a magnification of $250 \mathrm{X}$ after etching. Figure 2 illustrates the condition of the inner and outer surfaces of the inner tube of the fueled liner $B$. Views were taken both of the parent metal and of the longitudinal seam weld. No appreciable reaction between the fuel and the tube was noted as seen in views $C$ and $D$. The reaction is minimal considering the age and thermal history of the capsule. In Figure 3 similar views are presented for both surfaces of the outer tube of liner $B$. No evidence of fuel-1iner reaction was apparent. Figure 4 reveals the inner surface of the bottom cap which was in contact with the fuel. There is no significant indication of any reaction. It is interesting, however, to note that the grain size of the metal in the bottom cap is much larger than in the tubing (Views $A$ and $C$, Figure 3). For comparison, views of the inside surface of the longitudinal seam weld of the outer tube of the unfueled liner and of the outer surface of the circumferential weld are given in Figures 5 and 6.

The five liner samples used for the metallographic study were also subjected to microhardness measurements at LASL to evaluate the characteristics of the metal. Results of microhardness measurements are given on page 12 . 


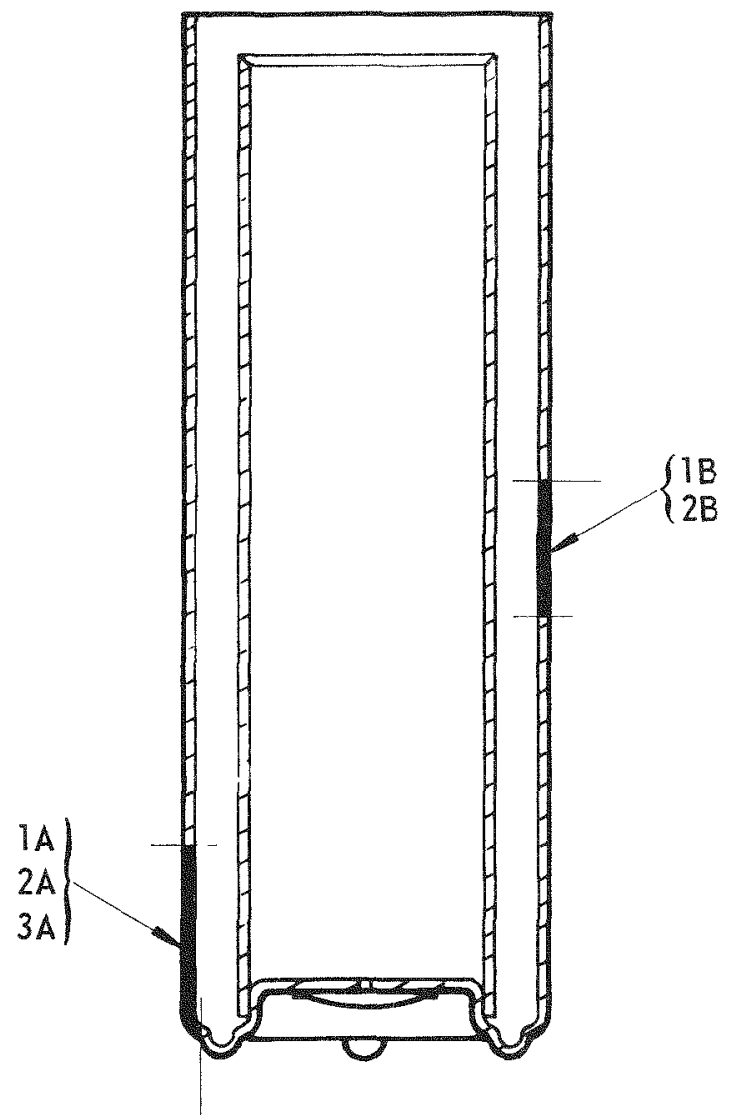

Figure 1 SNAP-27 Liner Assembly

Showing Location of Metallographic Sections 


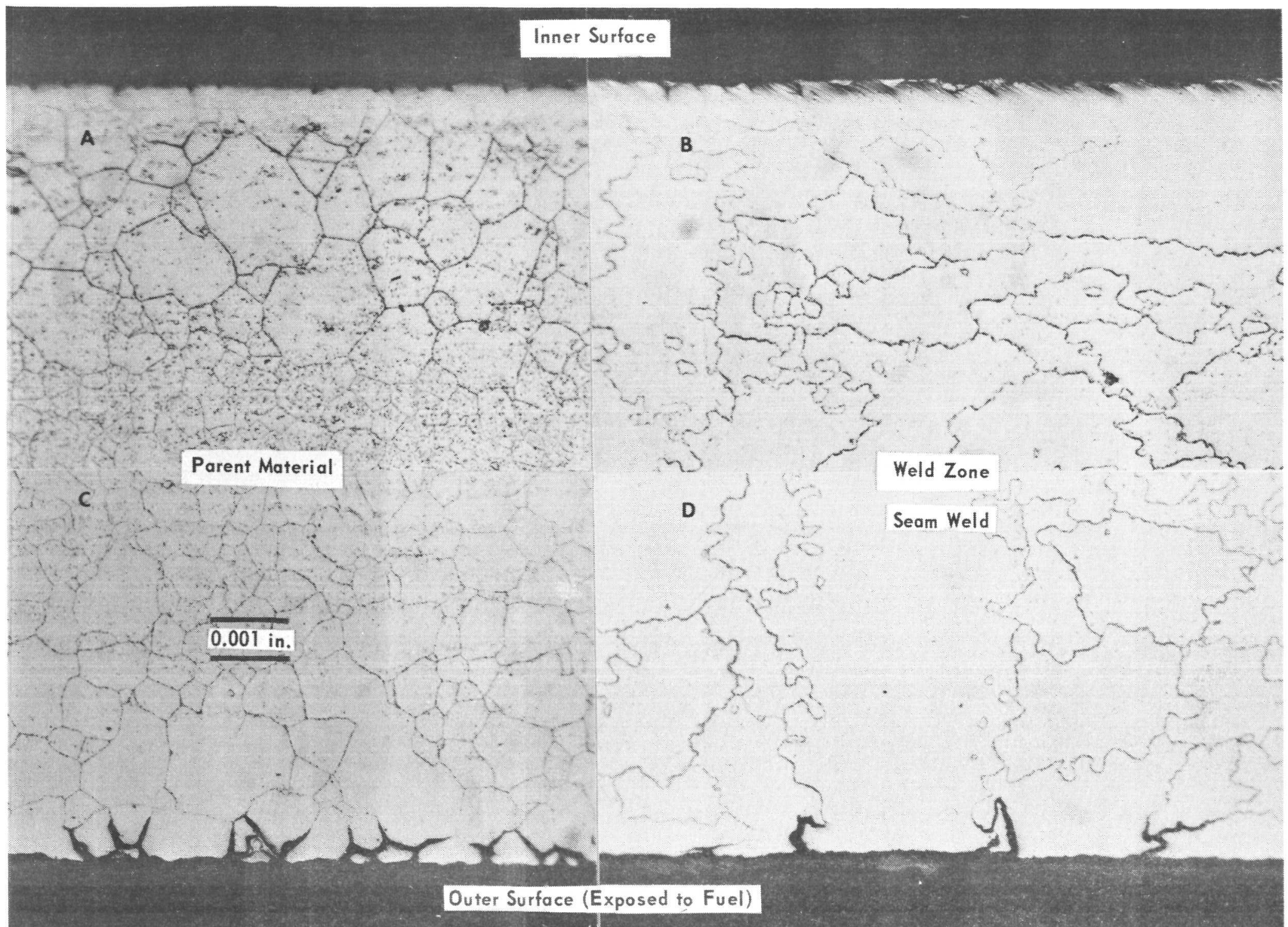

FIGURE 2: Metallographic section of inner tube of liner B as viewed along axis of tube. 250x-etched 


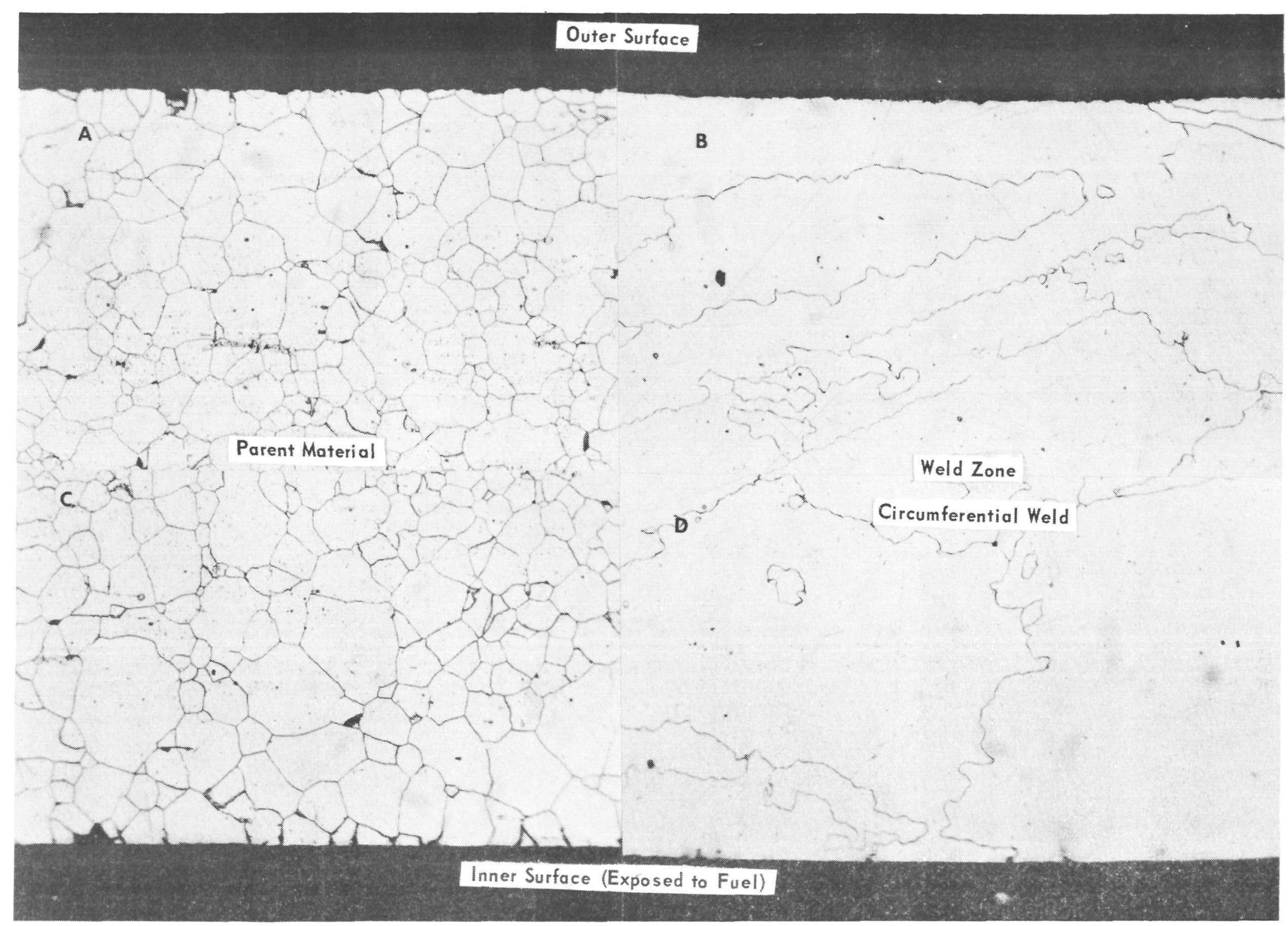

FIGURE 3: Metallographic section of outer tube of liner $B$ as viewed normal to axis of tube. 250x-etched 


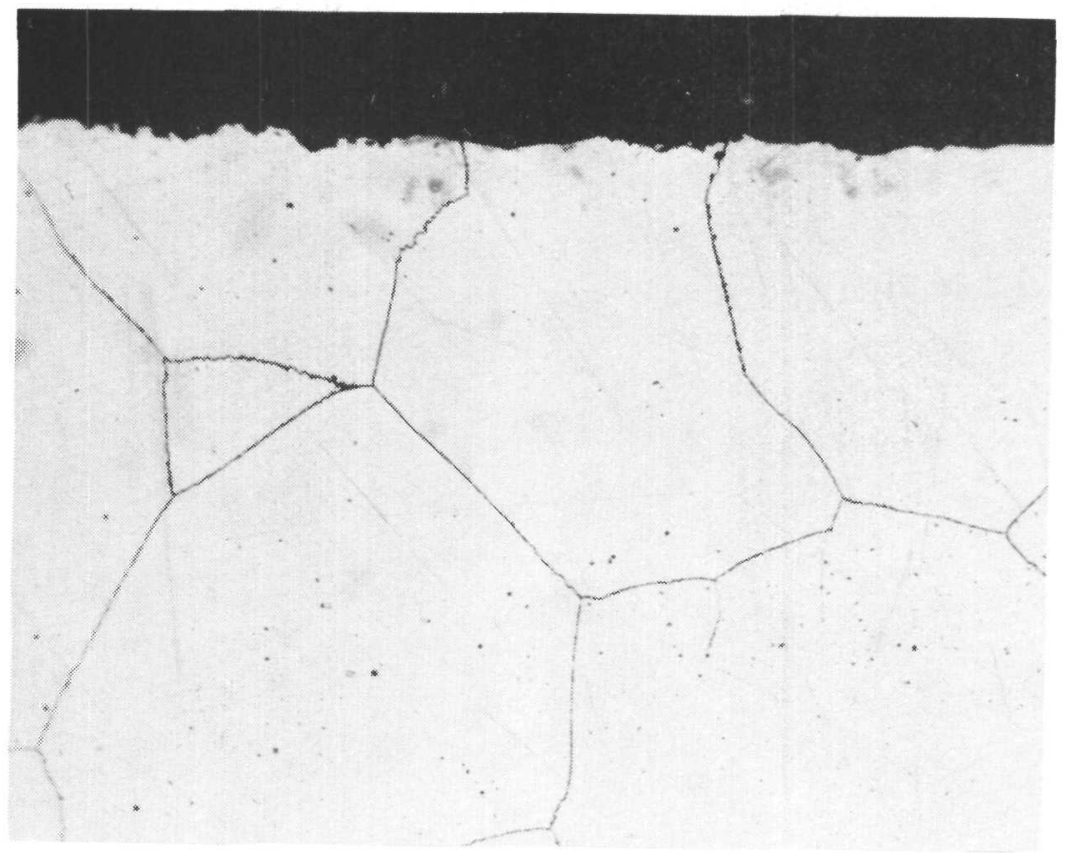

FIGURE 4: Metallographic section of inner surface of bottom cap of liner B normal to axis of 1iner. 250X-etched

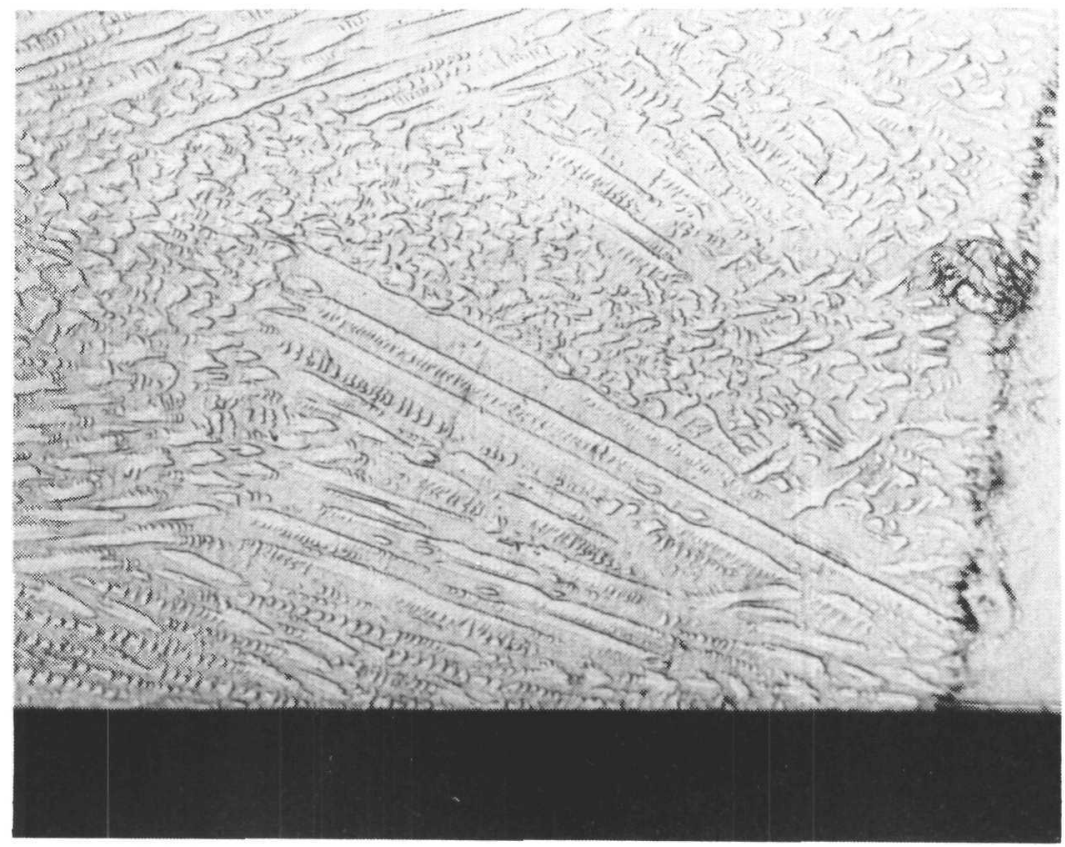

FIGURE 5: Metallographic section of seam weld of outer tube of empty liner as viewed along axis of 1iner. 250X-etched 


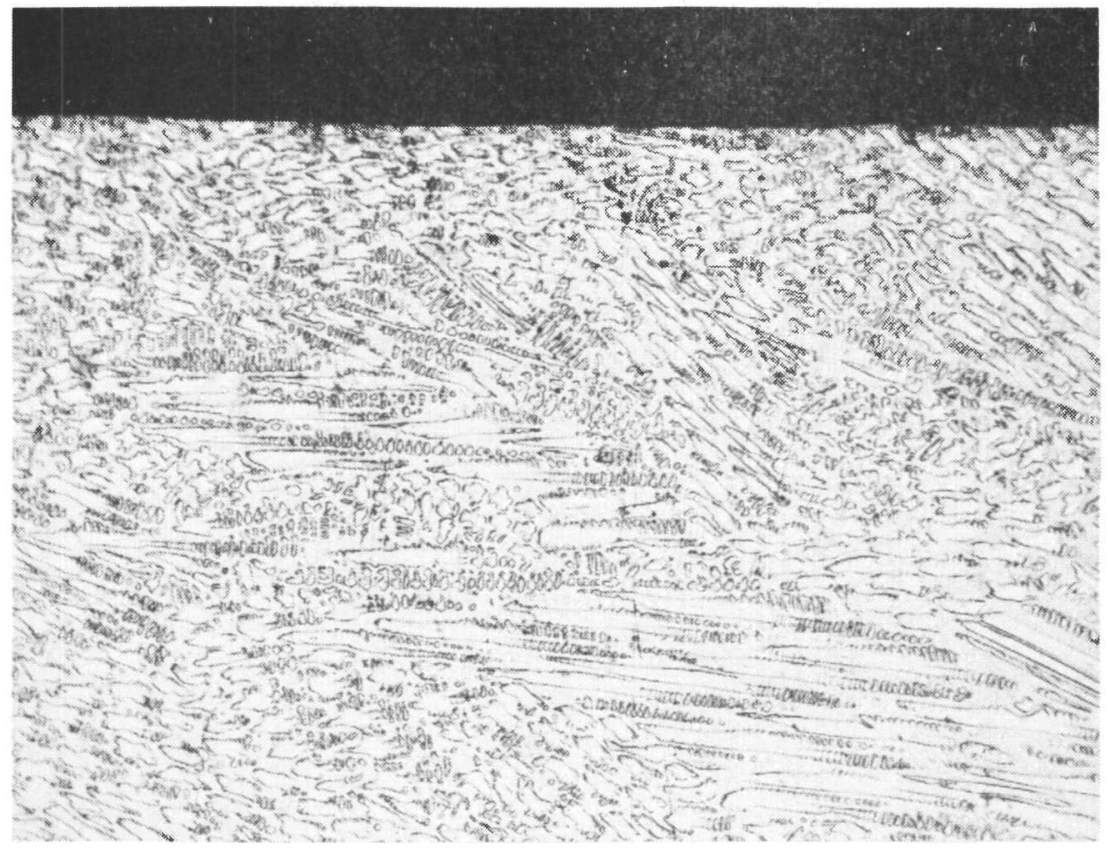

FIGURE 6: Metallographic section of outer surface of circumferential weld of empty liner normal to liner axis. 250X-etched 


\begin{tabular}{|c|c|c|}
\hline Samples & Location & DPH $(100-\mathrm{g}$ load $)$ \\
\hline $1 \mathrm{~A}$ & $\begin{array}{l}\text { fine grained } \\
\text { base metal }\end{array}$ & 314,336 \\
\hline $1 \mathrm{~A}$ & heat affected zone & $319,327,333$ \\
\hline $1 \mathrm{~A}$ & weld & $363,345,354$ \\
\hline $1 \mathrm{~A}$ & $\begin{array}{l}\text { coarse grained } \\
\text { base metal }\end{array}$ & $283,297,297$ \\
\hline $2 \mathrm{~A}$ & $\begin{array}{l}\text { fine grained } \\
\text { base metal }\end{array}$ & 354,330 \\
\hline $2 \mathrm{~A}$ & heat affected zone & $360,363,380$ \\
\hline $2 \mathrm{~A}$ & weld & $360,345,357$ \\
\hline $2 \mathrm{~A}$ & $\begin{array}{l}\text { coarse grained } \\
\text { base metal }\end{array}$ & $294,302,292$ \\
\hline $1 B$ & $\begin{array}{r}\text { base metal location } 1 \\
\text { location } 2 \\
\text { location } 3\end{array}$ & $\begin{array}{lll}325, & 322, & 319 \\
299, & 322, & 342 \\
336, & 330\end{array}$ \\
\hline $2 \mathrm{~B}$ & base metal & $383,366,383,383$ \\
\hline $3 \mathrm{~A}$ & base metal & $366,357,360,366$ \\
\hline $3 \mathrm{~A}$ & we1d & $345,383,336,342$ \\
\hline
\end{tabular}

The microhardness readings show no anomalous values which would indicate age embrittlement of the material.

To check for gross hardening effects, sample IA was bent back and forth $90^{\circ}$ over a $1 / 8$ in. radius. The specimen survived two bends and broke at the third bend. Some indications of brittle failure were observed, but survival through two bends shows that any age-hardening was minimal.

The unexposed sample, 3A, was also bent and survived four bends. When failure occurred, it was ductile in nature.

Although slight age hardening of the Haynes-25 in FCA4 appears to have occurred when compared with the control sample, the effects are minimal.

II. Fuel Evaluation

1. Dose Rate Measurements - For these measurements the heat source 
was held horizontally on a heat sink and cooled with two 12-in. fans. Both neutron and gamma dose rate measurements were taken at various distances from the side and each end of the source.

The measurements are 1 isted in Table 1 and are compared with those made at time of encapsulation 26 months ago. The significant increase in the gamma radiation is due to the ingrowth of the thallium-208 isotope.

The neutron measurements were made using a Texas Nuclear Nemo spherical Neutron Dosimeter Series 9140, with a 10-in. diameter sphere. The gamma measurements were made with a Victoreen Radector III Gamma Survey Meter having an accuracy of $\pm 20 \%$. Both instruments were calibrated before and after the measurements.

2. Helium Retention Studies - The study of the helium content of the capsule was performed in two parts. First the quantity of helium in the capsule which had escaped from the fuel was determined before the fuel was removed. Then the helium still retained by the fuel was evaluated.

To obtain the quantity of helium released by the fue 1 the apparatus shown in Figure 7 was used. Pressure measurements were made with a Mode1 $100 \mathrm{H}$ MKS Baratron pressure transducer. Procedures for determining the volume of the system and the amount of helium is described in more detail in Appendix A.

A special fixture was designed to accommodate the SNAP-27 heat source capsule. It is shown schematically in Figure 8. Temperature measurements were made during the entire process by means of six thermocouples strapped to the capsule. The thermocouples were positioned to avoid contact with the wall of the drilling fixture. A multipoint recorder was used to continuously record the temperatures. The location of each thermocouple is shown schematically in Figure 9. From the thermocouple readings it was hoped to determine whether one or both of the burst discs on the liners had been ruptured. The condition of the discs would control the helium content of the capsule at time of drilling which in turn would affect the thermal conductivity characteristics of the capsule and the temperatures at the thermocouples. Drilling was accomplished with a hand drill and a carbide drill bit brazed to a steel shaft. $0-r i n g$ seals around the shaft helped maintain the necessary vacuum during drilling. The dome end of the capsule was drilled first.

The gas data are summarized in Table 2. The values for the dome end are low because the drill was forced from the drilling fixture by the pressure of helium when the strength member was penetrated. As a result, some of the gas escaped. The excessive pressure was caused because only the $311.2 \mathrm{cc}$ standard volume was open to the system. The pressure indicated that the burst disc on the dome end liner was ruptured. From a knowledge of the weight of the drill and of the volumes of the capsule, a minimum helium content of $445 \mathrm{cc}$ was calculated for the dome end of the capsule. The dome end between the strength member and the liner was then evacuated 
Table 1

NEUTRON AND GAMMA DOSE RATE MEASUREMENTS

FOR SNAP- 27 FCA4

Side

Center of source to

Center of Detector (cm)

\section{0}

25

40

50

100

200

40

50

60

100

120

200

40

50

60

100

120

200

$5-27-68$
1769
1225
535
365
99
31

Neutron

(mrem/hr)

$\frac{(\text { mrem/hr }}{7-10-70}$

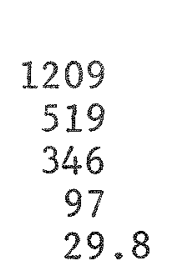

Total (mrem/hr) $\frac{\text { mrem/hr) }}{5-27-68 \quad 7-10-70}$

140

101

45

30

7.1

2.1

140
80
52
16
4

5-27-68

1909

1326

580

395

106.1

33.1

1349

599

398

113

33.8

Curved End

$\begin{array}{rrrrrr}404 & 396 & 20 & 40 & 424 & 436 \\ 213 & 204 & 9 & 21 & 222 & 225 \\ 137 & 137 & 5.5 & 12 & 142.5 & 149 \\ 45 & 45.1 & 1.9 & 3.3 & 46.9 & 48.4 \\ 33 & 31.9 & 1.3 & 2.2 & 34.3 & 34.1 \\ 14 & 13.9 & 0.6 & 1.0 & 14.6 & 14.9\end{array}$

Elanged Enda

$\begin{array}{rrrrr}304 & 12 & 28 & 306 & 332 \\ 156 & 6 & 14 & 163 & 170 \\ 97.2 & 3 & 8.5 & 102 & 106 \\ 33.2 & 1.3 & 2.5 & 36.3 & 35.7 \\ 24.1 & 1.0 & 1.7 & 26 & 25.8 \\ 12.4 & 0.6 & 0.8 & 13.6 & 13.2\end{array}$

a Readings taken through $1 / 4 \mathrm{in.}$. thick stainless steel handling plate bolted to flange. 


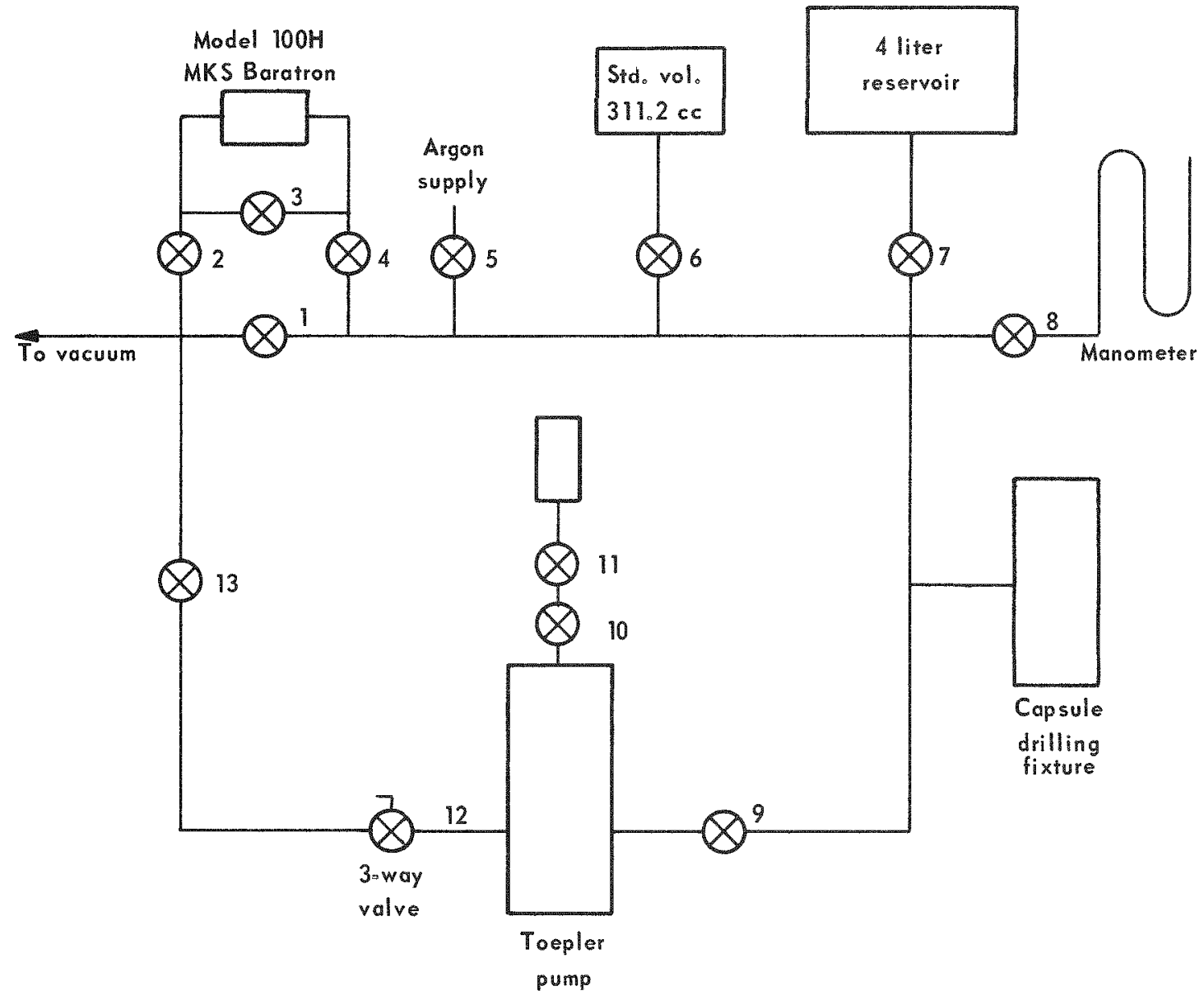

FIGURE 7 - Schemacic diagram of nelium release measuring apparatus 


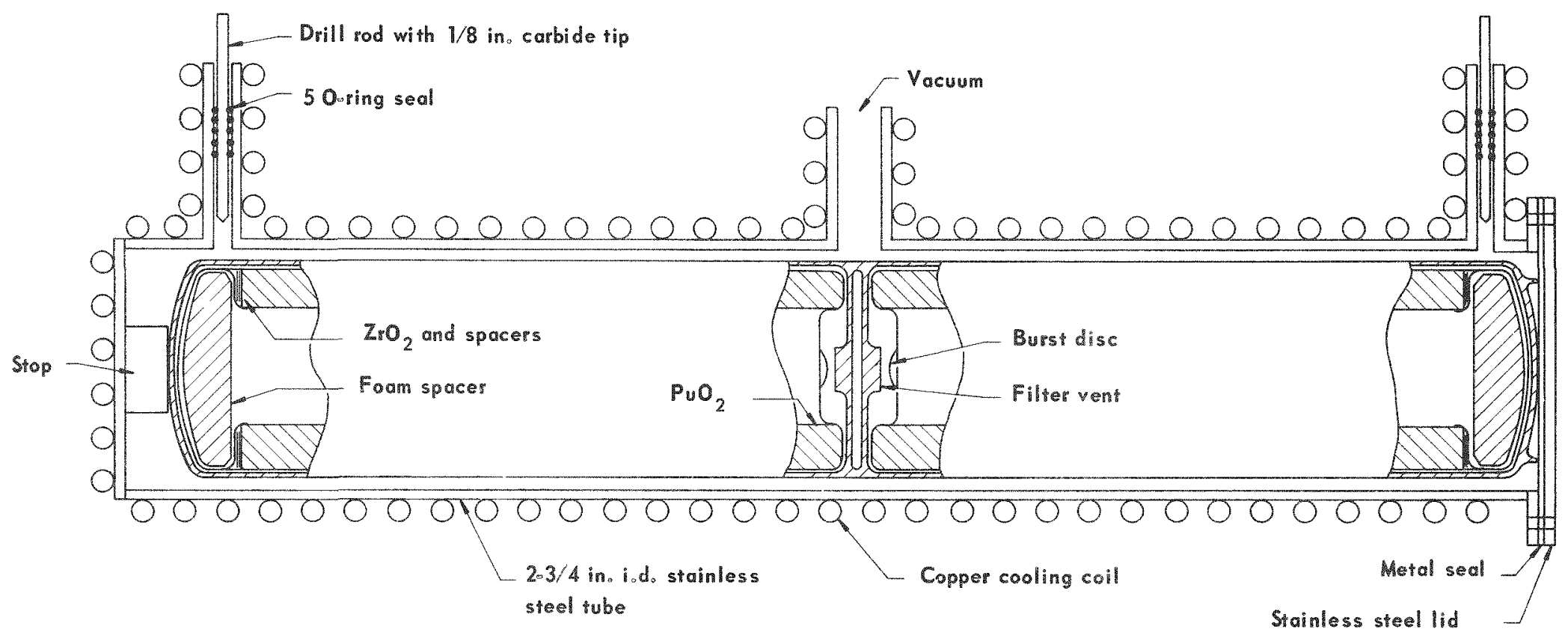

FIGURE \& - Schematic diagram of drilling fixture 


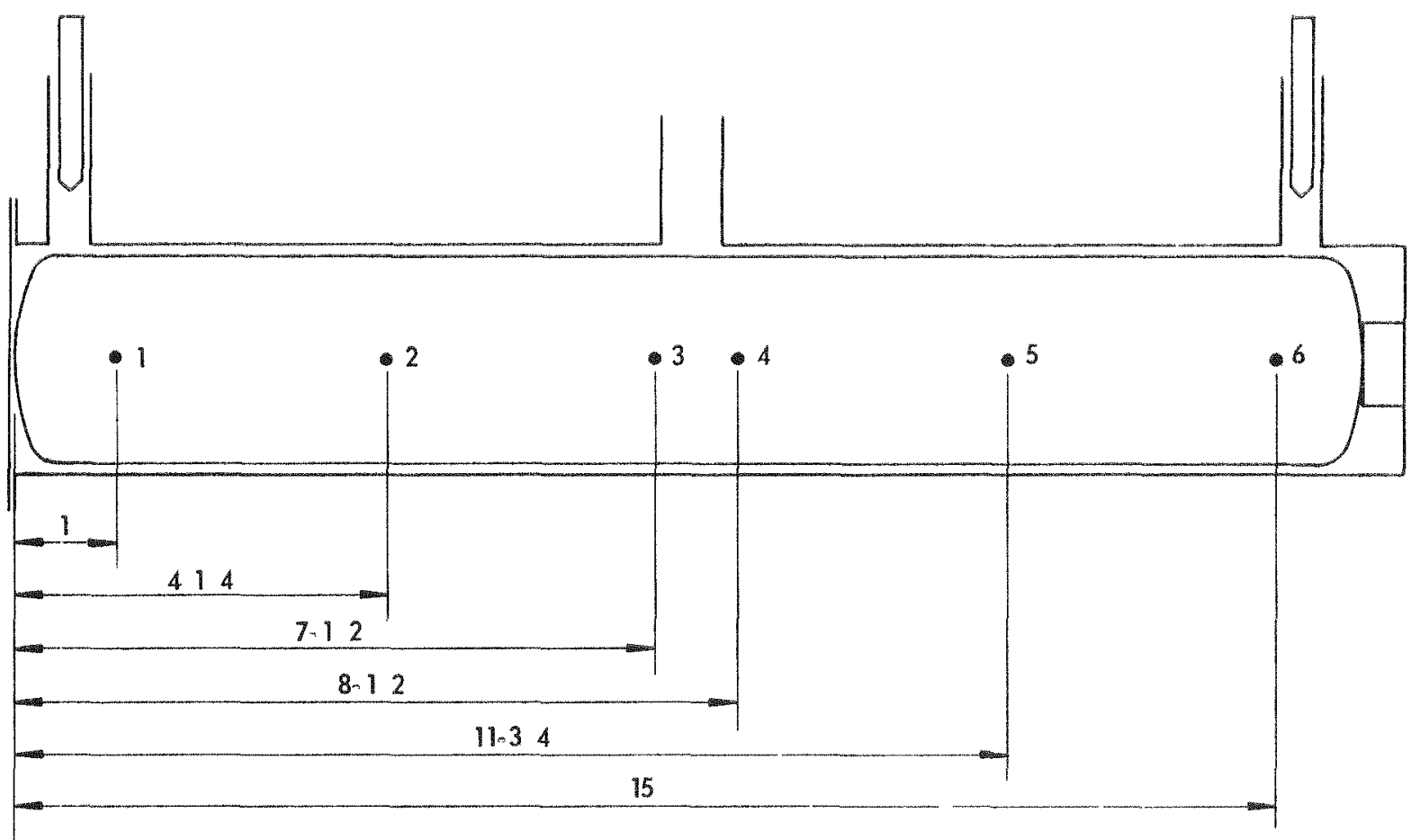

All dimensions in inches

FIGURE 9 - Scnematic aiagram of Lnermocouple locations 
until the thermocouple readings stabilized. The dome liner was drilled and the volume of gas released was measured. The volume was calculated to be $90 \mathrm{cc}$ as 1 isted in Table 2. After further evacuation, the strength member of the flange end was drilled. No gas was collected. Presumably any gas which may have been present in this section of the capsule had been removed through the vents by prior pumpings on the dome end. Drilling through the liner produced $728 \mathrm{cc}$ of helium indicating that the flange liner burst disc was still intact. This volume of gas is considered to be more accurate than those volumes for the dome end because there was no evidence that any of the gas collected from the flange end was lost.

The sequence of operations and the time required for each are illustrated in Figure 10 .

The numerical values used for the void volume of the fuel annulus and the center cylindrical volume of the liner were calculated rather than measured because measurements of the volume of the system after drilling was complicated by several factors such as the complexity of the free volume of the system which in some cases included the free volume of the microspheres, the volume of the apparatus, the volume of the space between the filters, and the volume between the strength member and the Iiner. The volumes were determined using a water measurement method with representative capsule components. Adjustment for fuel volume was based on the particle density of the fuel.

A trace of the temperature profile of the various thermocouples is given in Figure 10, and the temperature drop for each thermocouple after each operation is given in Table 3. From this table it appears that the dome end burst disc was ruptured while the flange end burst disc was not. This conclusion is supported by the data in Table 2 because no gas was collected after drilling through the strength member at the flange end.

Table 2

SUMMARY OF HELIUM MEASUREMENTS ON SNAP -27 FCA4

$\underline{\text { Region }}$

Between liner and strength member

Fuel annulus and central void
Amount of Helium at STP (cc)

Dome End Flange End

445

0

90

728

Tota 1

535
728 


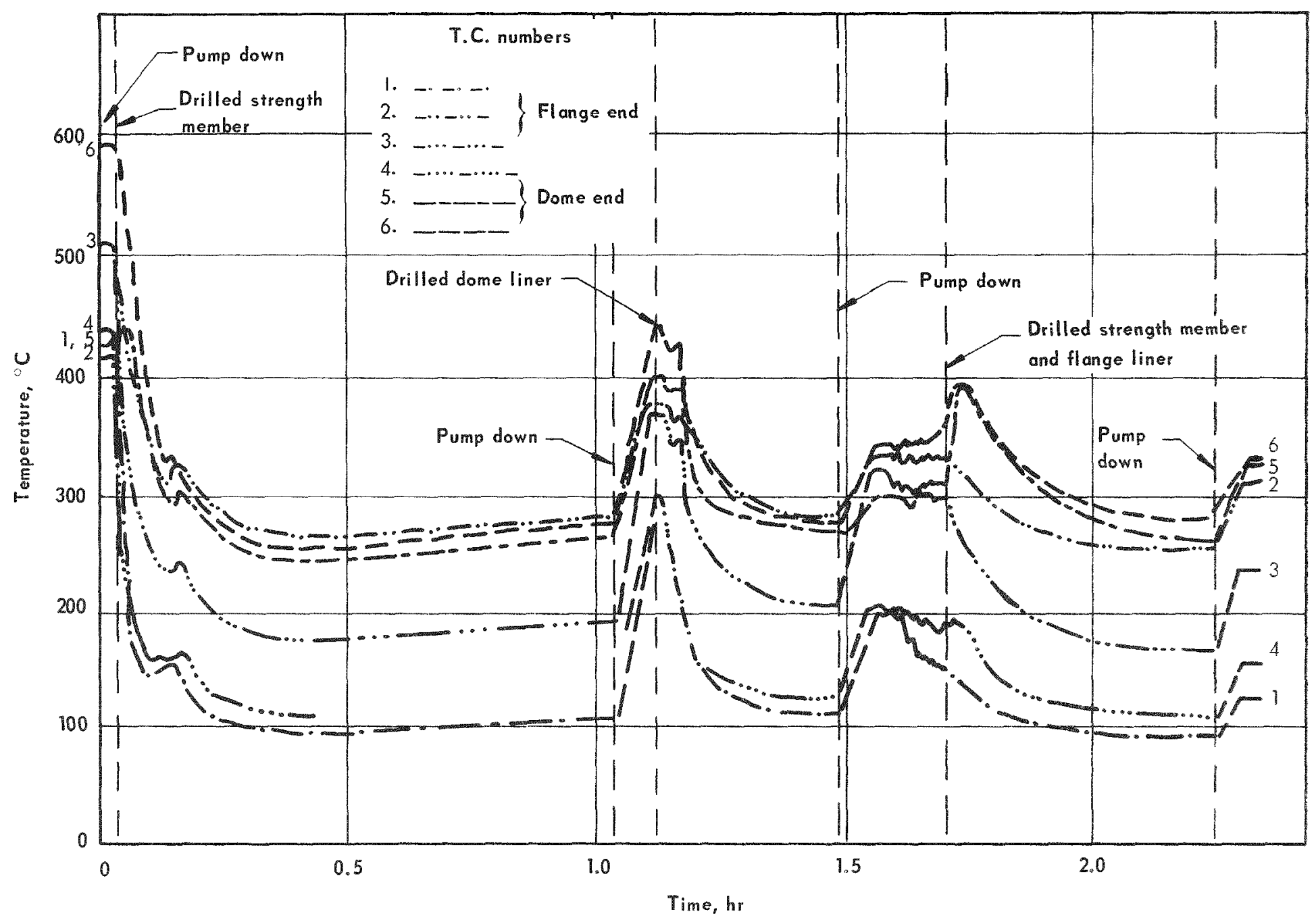

FI JURE 10 - Trace of cemperature profiles on thermocouples

in SNAP-27 heat source capsule during helium release measurements 
Table 3

TEMPERATURE DATA ON SNAP-27 FCA4

DOME END ${ }^{a}$

Thermocouple Number

\begin{tabular}{ccccccc}
\hline \multicolumn{5}{c}{ (flange end) } & & \multicolumn{3}{c}{ (dome end) } \\
427 & 2 & 3 & 4 & 5 & 6 \\
& 415 & 510 & 440 & 425 & 590 \\
96 & 265 & 175 & $\sim 120$ & 245 & 255 \\
278 & 377 & 368 & $\sim 300$ & 400 & 440 \\
-149 & -38 & -142 & $\sim-140$ & -25 & -150
\end{tabular}

Dri11 Liner

Before drilling (D)

278

377

$368 \sim 300$

400

440

After drilling (E)

110

280

$205 \quad 125$

270

280

After pump dow (F)

200

335

$320 \quad 200$

$300 \quad 340$

$\Delta T(D-F)$

$-78$

$-42$

$-48 \quad-145$

$-100 \quad-100$

Total $\triangle T(A-F)$

$-227$

$-80$

$-190 \quad-240$

$-125$

$-250$

a All values are given in ${ }^{\circ} \mathrm{C}$. 
Table 3 (Continued)

FLANGE ENDa

Thermocoup le Number

\begin{tabular}{|c|c|c|c|c|c|c|}
\hline \multirow[b]{2}{*}{$\frac{\text { Dril1 strength Member }}{\text { and Liner }}$} & \multicolumn{3}{|c|}{ (flange end) } & \multicolumn{3}{|c|}{ (dome erid) } \\
\hline & 1 & 2 & 3 & 4 & 5 & 6 \\
\hline Before drilling (G) & 200 & 335 & 320 & 200 & 300 & 340 \\
\hline After drilling (H) & 90 & 255 & 165 & 110 & 260 & 280 \\
\hline After pump down (I) & 120 & 310 & 235 & 150 & 325 & 330 \\
\hline$\Delta T \quad(G-I)$ & -80 & -25 & -85 & -50 & +25 & -10 \\
\hline Total $\wedge \mathrm{T}(A-I)$ & -307 & -105 & -275 & -290 & -100 & -260 \\
\hline
\end{tabular}

a 11 values are given in ${ }^{\circ} \mathrm{C}$. 
When the strength member on the dome end was dri1led, the temperature drop in both ends after pump down $[\Delta \mathrm{T}(\mathrm{A}-\mathrm{C})$ of Table 3$]$ was about the same suggesting that the helium measured came from the void space between the 1 iner and strength member in both halves of the capsules. The configuration of the capsule shows this to be true if the vents are considered to be open channels between the two halves. However, the volume of gas measured was quite high suggesting that one of the burst discs had ruptured. Drilling of the dome end liner produced a relatively small amount of helium and a much greater drop in temperature after pump down $[\Delta T(D-F)$ of Table 3] in the dome end thermocouples than in the flange end thermocouples. This suggests that the dome end burst disc ruptured as referred to previously in Table 2. The condition of the discs was confirmed visually when the strength member (clad component) was cut away from the liners after the fuel had been removed. The dome disc was ruptured whereas the flange disc appeared intact. The total temperature drop [ $\triangle \mathrm{T}(\mathrm{A}-\mathrm{I})$ of Table 3$]$ in the dome end was about the same as the total temperature drop in the flange end. This would be expected if all of the helium had been removed from the void volumes of each half.

Because it appeared that the burst disc on the flange liner had remained intact, it was interesting to calculate the pressure differential across the disc to determine what stresses it could withstand after being aged for $2.25 \mathrm{yr}$. The calculation was made after the dome liner had been evacuated, but before the flange liner was opened to give the maximum pressure which would exist across the disc.

Upon drilling through the flange liner the helium expanded into a total volume comprising the following components.

$$
\begin{aligned}
& \text { Large reservoir........ } 3994.1 \mathrm{cc} \\
& \text { Piping and drill fixture...... } 277.6 \\
& \text { Capsule ........ } \frac{674.1}{4945.8 \mathrm{cc}}
\end{aligned}
$$

The gas pressure was $11.2 \mathrm{~cm} \mathrm{Hg}$. The free volume of the flange liner as determined by water measurements and from the particle density of the fuel was $308.5 \mathrm{cc}$. Therefore, the pressure at room temperature in the liner before drilling was $179 \mathrm{~cm} \mathrm{Hg}$. As seen in Figure 10, the strength member temperature was $315^{\circ} \mathrm{C}\left(600^{\circ} \mathrm{F}\right)$ for about $15 \mathrm{~min}$ before opening the liner. From the data in the General Electric summary report ${ }^{2}$ it was estimated that the bulk helium temperature at the disc would be about $900^{\circ} \mathrm{F}$. Therefore, the pressure in the liner would be $462 \mathrm{~cm}$ or $6.08 \mathrm{~atm}$ at this temperature indicating the magnitude of the pressure differential across the disc.

2 SNAP-27 Summary Report DIN, GEMS 402, General Electric Company, (July $15,1970), \mathrm{pp}, 6-17$. 
Following the determination of the volume of helium in the capsule released by the fuel, experiments were performed on fuel samples to estimate the amount of helium retained by the microspheres.

Representative samples of microspheres from each of the capsule liners and a composite ( $1: 1)$ sample of both liners were used for this study. The data collected on each sample were corrected back to the day the capsule was opened. The information then could be combined with the data collected during the opening of the capsule to provide a value for the amount of helium present at that time.

Approximately $0.250 \mathrm{~g}$ of microspheres from Liner A (dome end) were used in the first experimental run. The sample was placed in the helium release experimental setup and heated to approximately $1980^{\circ} \mathrm{C}$ in vacuum. The sample was maintained at this temperature until a decrease in the helium release rate was noted. The sample was cooled and taken off test when it was determined that the helium release rate had decreased to the background rate of the measuring equipment. The results of this experiment are shown in Table 4.

Another portion of the same sample of microspheres was tested after it was determined that the results from the first portion did not correspond with the results from the other samples tested. The results for this sample are also shown in Table 4.

Two portions of the sample of microspheres from Liner B (flange end) were tested in exactly the same manner as those from Liner $A$. The results are given in Table 4.

The Composite A-B was prepared as a uniform mixture of microspheres from Liners $A$ and $B$. One portion of the sample of the composite was tested and the results are listed in Table 4.

Table 4

HELIUM INVENTORY DATA FOR SNAP-27 FCA4

\begin{tabular}{lccc} 
Sample & $\begin{array}{c}\text { Sample Weight } \\
\text { S }\end{array}$ & $\begin{array}{c}\text { Helium Inventory } \\
(\mathrm{cc} / \mathrm{g})\end{array}$ & $\begin{array}{c}\text { Helium Inventory } \\
\text { (expressed in months) }\end{array}$ \\
Liner A-1 & 0.250 & 0.2429 & 5.62 \\
Liner A-2 & 0.198 & 0.1979 & 4.58 \\
Liner B-1 & 0.279 & 0.8350 & 19.33 \\
Liner B-2 & 0.164 & 0.8674 & 20.08 \\
Composite AB & 0.248 & 0.7691 & 17.80 \\
\multicolumn{2}{c}{ Corrected to date of capsule opening. }
\end{tabular}


As seen in Table 4, there is an apparent anomaly in the experimental results. The data on the samples from Liner A do not correspond with the data on the other samples. When these data are combined with the capsule opening data, it becomes obvious that the sample from Liner A was not representative. It is assumed that the Liner A sample was from the stratified high tempexature region of the liner and, as a consequence, contalined much less helium.

Since the data from the Liner A sample are questionable, they were eliminated from further consideration. However, the data for the composite sample approximately equal the data for the Iiner B sample. The composite was prepared as a uniform mixture of microspheres from Liners $A$ and $B$; and if a sample ratio of $1: 1$ is assuned, it can be stated that the data collected on the composite sample should reflect the approximate amount of helium retained by the microspheres in both Liner $A$ and Liner $B$ since they were exposea to the sane thermal history during encapsulation. With the above assumptions, it is now possible to average the helium inventory values obtained for the samples from Liner $B$ and the composite sample. This average helium inventory value is 0.8236 $\mathrm{cm}^{3}$ of helium per gram of $\mathrm{PuO}_{2}$ which is equivalent to a helium production of 19.06 months being retained by the fuel.

The above inventory value together with the gas volumes in Table 2, were used to determine the total amount of helium present in the SNAP-27 FCA4 just prior to opening. These data are presented in Table 5. The volume of helium retained by the fuel in each liner was determined by multiplying the average value of $0.8236 \mathrm{~cm}^{3} \mathrm{He} / \mathrm{g} \mathrm{PuO}_{2}$ by the fuel weight in each liner listed in the table.

Table 5

AMOUNT OF HELIUM PRESENT IN SNAP-27 FCA4 PRIOR TO OPENING

\begin{tabular}{|c|c|c|c|}
\hline & Liner A & Liner B & FCA4 Capsule \\
\hline Fuel loading ( $\mathrm{g} \mathrm{PuO}_{2}$ ) & 1913.41 & 1884.8 & 3798.21 \\
\hline $\begin{array}{l}\text { Amount of helium } \\
\text { released on opening }\left(\mathrm{cm}^{3}\right)\end{array}$ & 535 & 728 & 1263 \\
\hline $\begin{array}{l}\text { Amount of helium } \\
\text { retained by the fuel }\left(\mathrm{cm}^{3}\right)\end{array}$ & 1575 & 1552 & 3128 \\
\hline $\begin{array}{l}\text { Total amount of helium } \\
\text { present }\left(\mathrm{cm}^{3}\right)\end{array}$ & 2111 & 2280 & 4391 \\
\hline Percent released of total & & 32 & \\
\hline
\end{tabular}


The amount of helium which would have been generated during the encapsulation period of 2.25 yr was calculated using the theoretical helium generation rate of $1.67 \times 10^{-8} \mathrm{~cm}^{3}$ of helium per gram of Puo, per second. The calculated values of gas based on the fuel loading of each liner are given in Table 6 along with the experimental values from Table 5.

Table 6

COMPARISON OF THE EXPERIMENTAL AND THEORETICAL HELIUM INVENTORIES OF SNAP- 27 FCA 4

\begin{tabular}{|c|c|c|c|}
\hline & Liner A & Liner B & FCA4 Capsule \\
\hline $\begin{array}{l}\text { Calculated helium } \\
\text { inventory }\left(\mathrm{cm}^{3}\right)\end{array}$ & 2272 & 2235 & 4507 \\
\hline $\begin{array}{l}\text { Experimenta11y determined } \\
\text { helium inventory }\left(\mathrm{cm}^{3}\right)\end{array}$ & 2111 & 2280 & 4391 \\
\hline
\end{tabular}

The data show a reasonable comparison between the theoretical values and the experimentally determined ones. Since the fuel had a prior encapsulation history before being loaded into FCA4, the experimenta11y determined values should be greater than the theoretical values listed in Table 6. This is true in the case of Liner B. In the case of Liner A, however, the amount of helium released on capsule opening was an estimated value rather than a measured value and the sample of microspheres from this liner used for the helium inventory measurement was not representative of the fuel. Actually the quantity of helium recovered from Liner A should have been greater than for Liner $B$ for two reasons.

\section{There was more fuel in Liner $A$.}

2. The fuel in Liner A was made up of $84 \%$ of fuel from SNAP-19 capsules and $16 \%$ of bonded fuel whereas the fuel in Liner B consisted entirely of SNAP-19 fue 1.

The SNAP-19 fuel had been subjected to a severe thermal environment which should have driven off much of the helium before being used for fueling FCA4. On the other hand, the bonded fuel which had not experienced such a severe thermal history should have contained more helium at time of encapsulation. Therefore Liner A should have released more helium when it was opened. The capsule should have contained at least twice the quantity of gas obtained from Liner B or $4560 \mathrm{cc}$. Therefore the volume of gas in the fuel at time of encapsulation of FCA4 should have been $(4560-4507) \mathrm{cc}$ or $53 \mathrm{cc}$. This amount is equivalent to the quantity of gas which would have been generated by the $3798.21 \mathrm{~g}$ of fue 1 in 10 days. 
The gas pressure which could have existed in FCA4 at an assumed operating temperature of $1500^{\circ} \mathrm{F}\left(815^{\circ} \mathrm{C}\right)$ would be $23.56 \mathrm{~atm}$. The value is based on the free gas volume of the capsule of $674.1 \mathrm{cc}$ and a helium content of $4391 \mathrm{cc}$. This pressure would apply after the fuel had been encapsulated for $2.25 \mathrm{yr}$ if all the helium was released in this period. However, on 1 y $32 \%$ of the helium was released by the fuel in Liner $B$. Therefore the pressure first created at $1500^{\circ} \mathrm{F}$ would be $7.54 \mathrm{~atm}$. The pressure of $23.56 \mathrm{~atm}$ would not be reached until after the fuel had been at this temperature for several years. After several years though, the pressure would be somewhat higher due to the additional helium generated during this period which in turn would be offset to some extent by the decrease in temperature from the additional decay of the fuel and the possible increase in the capsule volume due to creep. At higher temperatures experienced during reentry the bulk of the gas would escape from the fuel in a matter of a few minutes. Again for FCA4 a maximum pressure of 30.87 atm would be reached at a temperature of $2085^{\circ} \mathrm{F}\left(1140^{\circ} \mathrm{C}\right)$. At a temperature of $2400^{\circ} \mathrm{F}\left(1315^{\circ} \mathrm{C}\right)$ a 11 the gas would be driven from the fuel very rapidly reaching a pressure of $34.69 \mathrm{~atm}$.

As noted previously the fuel in FCA4 had experienced a rather unusual thermal history. In addition the fuel, while in the SNAP-19 capsules, had been exposed to severe thermal conditions which would account in part for low calculated volume of retained helium of $53 \mathrm{cc}$ at time of encapsulation in FCA4. A summary of the time-temperature data for the fuel from the four SNAP-19 capsules used is given in Table 7 . Similar data for FCA4 during its life are given in Table 8. For FCA4 the temperatures for $850^{\circ} \mathrm{F}$ and above apply to the capsule while under test. For lower temperatures the capsule was in storage.

It can be seen from the data for Liner B in Table 5 that the helium retained by the fuel was $68 \%$ of the total in spite of the elevated thermal environment experienced by the fuel. The fuel in the prime capsules prior to launching should not normally be subjected to the thermal regime imposed on FCA4 and should be able to retain at least as much helium as the fuel did in FCA4. In addition because of the older fuel used in FCA4 there would be a greater tendency for helium release.

Table 7

THERMAL HISTORY OF SNAP-19 CAPSULES

\begin{tabular}{|c|c|c|c|c|c|c|c|c|c|c|}
\hline & & \multicolumn{9}{|c|}{ Time at Temperature (hr) } \\
\hline Capsule & ${ }^{\circ} \mathrm{F}$ & 350 & 380 & 650 & 825 & 900 & 1000 & 1100 & 1325 & 1425 \\
\hline Number & ${ }^{\circ} \mathrm{C}$ & 177 & 193 & 343 & 441 & 482 & 538 & 593 & 718 & 774 \\
\hline 307 & & & & 1008 & 6192 & 2064 & 1488 & & & \\
\hline 341,360 & & & & & & & & 2400 & 672 & 288 \\
\hline 346 & & 192 & 240 & 936 & 6192 & 2064 & 1488 & & & \\
\hline
\end{tabular}


Table 8

THERMAL HLSTORY OF SNAP-27 FCA4

\begin{tabular}{|c|c|c|c|c|c|c|c|c|c|c|}
\hline \multirow[b]{3}{*}{ Location } & \multicolumn{10}{|c|}{ Time at Temperature (hr) } \\
\hline & ${ }^{\circ} \mathrm{F}$ & 212 & 500 & 520 & 850 & 1050 & 1100 & 1200 & 1250 & 1350 \\
\hline & ${ }^{\circ} \mathrm{C}$ & 100 & 260 & 270 & 480 & 565 & 595 & 650 & 675 & 730 \\
\hline Mound & & $2253^{a}$ & $5^{t}$ & $30^{b}$ & & & & & & \\
\hline GE & & & $17616^{\circ}$ & 93 & & 39 & 3 & 20 & 121 & 166 \\
\hline TRW & & $2 \overline{253}$ & $17 \overline{621}$ & $\overline{123}$ & $\frac{350}{350}$ & 39 & 3 & 20 & $\overline{121}$ & 166 \\
\hline
\end{tabular}

a Fuel in liners $216 \mathrm{hr}$, in uncoated capsule $353 \mathrm{hr}$, in coated capsule 1684 hr.

Fuel in uncoated capsule.

Includes total time for coated capsule in GSC at Mound, GE, and TRW.

3. Fuel Fines Determination Following the helium measurement study, an evaluation of the present condition of the fuel in the capsule was undertaken. As part of the radiographic examination of the capsule, cobalt radiography was used to determine whether the fuel had changed position. No slumping of the fuel was detected. After the helium had been removed from the capsule, the capsule was cut in half at the center section weld to facilitate the extraction of the fuel. Then the flanged and dome clad ends and the liner caps were cut away to expose the liner cap weld and the zee-ring. Each half was doubly encapsulated in sealed containers and transferred under water to the fuel removal facility. The dome end liner, now designated Liner A, was opened first. The assembly, including the cladding, was placed in a water-cooled chill block and left overnight. A circumferential cut was made below the liner cap weld with compound snips and the remainder of the zee-ring was removed. All six shims were found still resting on top of the fue 1 column in the position that they were placed oxiginally. The shims were removed and the fuel was poured in increments of 200-300 $\mathrm{g}$ into a 6-in. diameter stainless steel screen pan. Each increment then was transferred to a stainless steel fuel container. The fuel flowed readily with about 10-15\% of fuel (as estimated visua11y) consisting of agglomerates less than $1 / 2 \mathrm{in.} x 1 \mathrm{in.} x 1 / 8 \mathrm{in.}$ in size. The agglomerates appeared to consist of thin layers which may have been formed in the hotter region of the fuel volume. The agglomerates broke up readily when shaken on the screen pan. The fuel was collected in seven fuel containers. Next the liner from the flange end, now called Liner B, was opened in the same manner as Liner $A$. The only difference was that 
this liner was stored in the chill block for two days before the zeering was removed. Again, the eight shims originally placed in the liner were found on top of the fuel. The fuel was free flowing during removal and devoid of clumps. The fuel was distributed among seven fuel containers. The weight of fuel in each batch for both liners is shown in column 2 of Table 9 . The zirconium dioxide filler in both liners was distributed throughout the fuel. The filler apparently was more evenly distributed throughout the fuel in the dome liner than in the flange liner. This difference will be discussed in more detail later.

After the fuel containers had been removed from the glovebox in which the fuel transfer was made the box was wiped down, and the wipings and the box filter were gamma-scanned to estimate the amount of plutonium remaining in the box. For the same reason the capsule metal components were also scanned. The results of the scan expressed in grams of isotope are as follows:

Dome Liner (A)

$\begin{array}{lc} & \begin{array}{c}\text { Residue } \\ (\mathrm{g} \text { isotope })\end{array} \\ \text { Metal components } & 0.267 \\ \text { Wipes } & \underline{0.238} \\ & 0.505\end{array}$

Flange Liner (B)

$\begin{array}{ll}\text { Metal components } & 0.151 \\ \text { Box filter } & 0.026 \\ \text { Wipes } & 0.425 \\ & 0.602\end{array}$

The metal components were sealed into a metal storage container to be held for future metallographic examination.

The elutriation column used originally for determining the fines content of microsphere fuel was modified in an attempt to measure the fines which existed in the FCA4 fuel at the time of its removal. The column was changed to obtain a continuous sample of the washings from each batch of fuel in the colum. Normally only the last $500 \mathrm{ml}$ of the 20 liters used for washing a batch was collected to determine the fines content of the batch. For this study, however, it was desirable to collect al1 the fines which were present in the fuel. After several batches of fuel from Liner B were washed, it became apparent that the fines measurements were on the low side. Accordingly another method for determining the fines content of the fuel was adopted. The method, in addition to providing more reliable data, allowed the fines to be 
Table 9

WEIGHT OF FUEL FROM BOTH LINERS AFTER WASHING AND SCREENING ${ }^{a}$

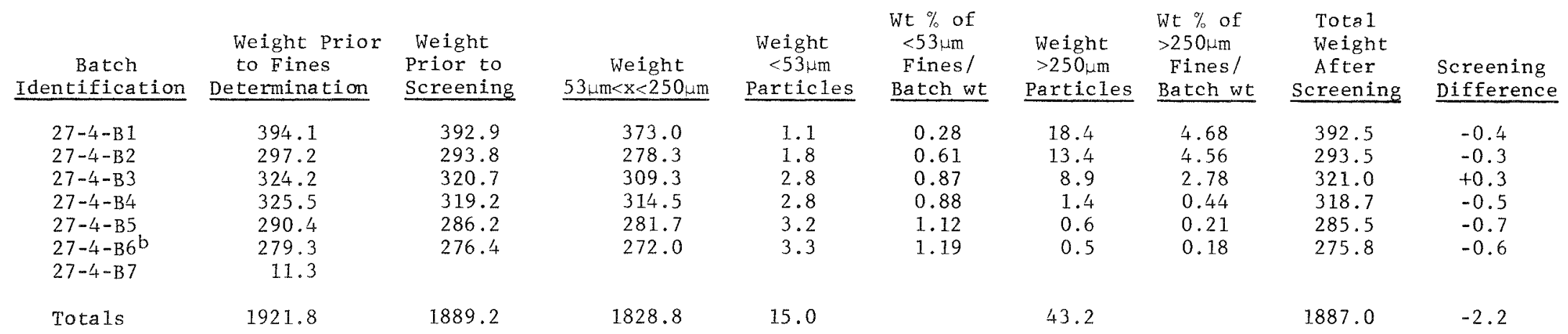

b 27-4-B7 (11.1g) combined with 27-4-B6 prior to washing.

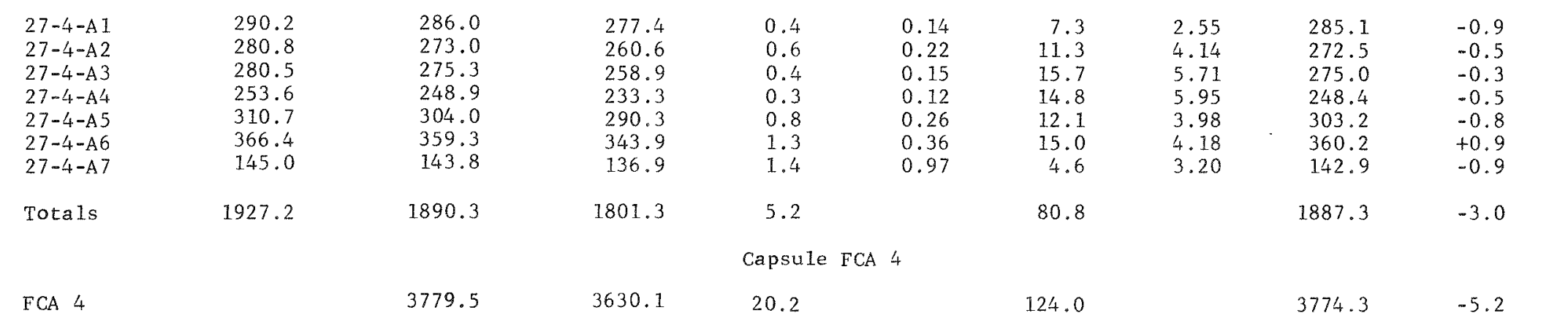

a All values given are grams of oxide except as noted. 
segregated into severa1 size ranges. The method consisted of placing a batch of fuel including the filler material on a $37 \mathrm{\mu m}$ screen and washing with about $400 \mathrm{ml}$ of washing solution. The fuel then in turn was placed on a $44 \mu \mathrm{m}$ screen and a $53 \mu \mathrm{m}$ screen. A11 the fuel from Liner A except batch 27-4-A7 was treated in this manner. Batch 27-4-A7 had been used previously for checking the elutriation column. In al1 cases the washings and sieve fractions were saved for analysis. The results of the analyses are listed in Table 10 and summarized in Table 11. The washings from the $37 \mathrm{\mu m}$ screen were allowed to stand and the supernatent liquid was decanted. The values for the plutonium in the decanted liquid are given in row one of the table. The values for the residue are given in row two. The values for the washings after the fuel had been placed on a $44 \mu \mathrm{m}$ screen and the 37-44 $\mathrm{\mu m}$ particles are shown in rows three and four. The values for the first and second washings from the $53 \mu \mathrm{m}$ screen and the $44-53 \mu \mathrm{m}$ particles are listed in rows five, six, and seven. Finally, each batch was washed in the elutriation column using 15 liters of washing solution. Samples of each solution were analyzed and the values are reported in the eighth row. A total of $22.496 \mathrm{~g}$ (isotope) of fines were removed by washing from six of the batches of fuel of the dome liner. To this value can be added the $0.505 \mathrm{~g}$ of fines detected on the capsule components and wipes by gamma scanning. The total fines content of $23.001 \mathrm{~g}$ is equivalent to $\frac{23.001}{6.6882} \times \frac{100}{178.1}$ or $1.97 \%$ of the fuel in the six batches. The factor 0.6682 is the ratio of isotope to oxide weights for the fuel at time of removal from the liner. The weight of fuel (1749.1 g) is the weight of the first six batches of fuel removed from Liner A less the weight of the filler $(33.1 \mathrm{~g})$ added to the liner originally.

Figures 11, 12, and 13 are representative views of the shape of particles in the three size ranges of fines removed from one of the batches of fuel from the $A$ liner. The larger pieces of material which are most noticeable in Figure 13 are assumed to be filler material.

The weight of particles $>250 \mu \mathrm{m}$ given in Table 9 totalled $80.8 \mathrm{~g}$ for Liner A. Of this weight, $49.2 \mathrm{~g}$ consisted of $\mathrm{PuO}_{2}$ as determined by calorimetxy. Therefore, the difference in weight of $31.6 \mathrm{~g}$ was assumed to consist of filler material. This assumption appears reasonable because the amount of filler added to the liner was $33.1 \mathrm{~g}$. For the $\mathrm{B}$ liner the weight of particles $>250 \mu \mathrm{m}$ in size amounted to $43.2 \mathrm{~g}$ as compared with $42.4 \mathrm{~g}$ of filler which was added to the liner. For this liner it appears that very little of the material consisted of $\mathrm{PuO}_{2}$ as contrasted with the findings for Liner A. Examination of the material from Liner A under a microscope revealed that the plutonium dioxide consisted of agglomerates in which two or more of the individual microspheres were bonded together. These findings coincide with the earlier observations which showed that the fuel when poured from Liner A had some large agglomerates whereas the fuel in Liner $B$ had none.

After washing, the fuel was screened to segregate the material in the 53 to $250 \mathrm{~km}$ range as required by the SNAP-27 fuel specification. The results of the screening operations are shown in Table 9 . The screening 
Table 10

FINES ANALYSIS OF FUEL FROM LINER A (DOME END)

\begin{tabular}{|c|c|c|c|c|c|c|c|c|}
\hline \multirow[b]{2}{*}{ Fraction ${ }^{a}$} & \multicolumn{6}{|c|}{ Batch Number ${ }^{a}$} & \multirow[b]{2}{*}{ Tota 1} & \multirow{2}{*}{$\begin{array}{l}\text { Fines } \\
\text { (wt } \%) \\
\end{array}$} \\
\hline & 1 & 2 & 3 & 4 & 5 & 6 & & \\
\hline$<37 \mu \mathrm{m}$ wash & 0.060 & 0.080 & 0.052 & 0.039 & 0.084 & 0.155 & 0.470 & 2.09 \\
\hline$<37 \mu \mathrm{m}$ fines & 0.777 & 0.373 & 0.510 & 0.580 & 0.875 & 1.275 & 4.390 & 19.51 \\
\hline $44 \mu \mathrm{m}$ wash & 0.051 & 0.000 & 0.162 & 0.010 & 0.087 & 0.009 & 0.319 & 1.42 \\
\hline 37-44 $\mu_{\mathrm{m}}$ fines & 0.383 & 0.723 & 0.207 & 0.429 & 0.724 & 0.844 & 3.310 & 14.71 \\
\hline Ist $53 \mu \mathrm{m}$ wash & 0.034 & 0.003 & 0.112 & 0.085 & 0.034 & 0.059 & 0.327 & 1.47 \\
\hline 2nd $53 \mu \mathrm{m}$ wash & 0.052 & 0.000 & 0.025 & 0.086 & 0.017 & 0.051 & 0.231 & 1.02 \\
\hline 44-53 um fines & 1.218 & 2.423 & 1.508 & 0.823 & 1.621 & 1.475 & 9.068 & 40.31 \\
\hline Column Wash & 1.840 & 1.545 & 0.120 & 0.006 & 0.135 & 0.735 & 4.381 & 19.47 \\
\hline Total & 4.415 & 5.147 & 2.696 & 2.058 & 3.577 & 4.603 & 22.496 & \\
\hline wt $\%$ fines & 19.63 & 22.88 & 11.98 & 9.15 & 15.90 & 20.46 & & \\
\hline
\end{tabular}

a A11 sieving was done using U. S. Standard sieves having a permissible variation in average opening of $7 \%$.

b A11 values are grams isotope except as noted. 
Table 11

SUMMARY OF FINES ANALYSIS OF FUEL FROM LINER A (DOME END)

\begin{tabular}{|c|c|c|c|c|c|c|c|c|}
\hline Size & \multicolumn{6}{|c|}{ Batch Number ${ }^{a}$} & \multirow[b]{2}{*}{ Total } & \multirow{2}{*}{$\begin{array}{l}\text { Fines } \\
\text { (wt \%) }\end{array}$} \\
\hline Range & $I$ & 2 & 3 & 4 & 5 & 6 & & \\
\hline$<37 \mu \mathrm{m}$ & 2.677 & 1.998 & 0.682 & 0.625 & 1.094 & 2.165 & 9.241 & 41.08 \\
\hline $37-44 \mu \mathrm{m}$ & 0.434 & 0.723 & 0.369 & 0.439 & 0.811 & 0.853 & 3.629 & 16.13 \\
\hline 44-53 $\mu \mathrm{m}$ & 1.304 & 2.426 & 1.645 & 0.994 & 1.672 & 1.585 & 9.626 & 42.79 \\
\hline Tota 1 & 4.415 & 5.147 & 2.696 & 2.058 & 3.577 & 4.603 & 22.496 & \\
\hline we $\%$ & 19.63 & 22.88 & 11.98 & 9.15 & 15.90 & 20.46 & & \\
\hline
\end{tabular}

a All values are grams isotope except as noted. 


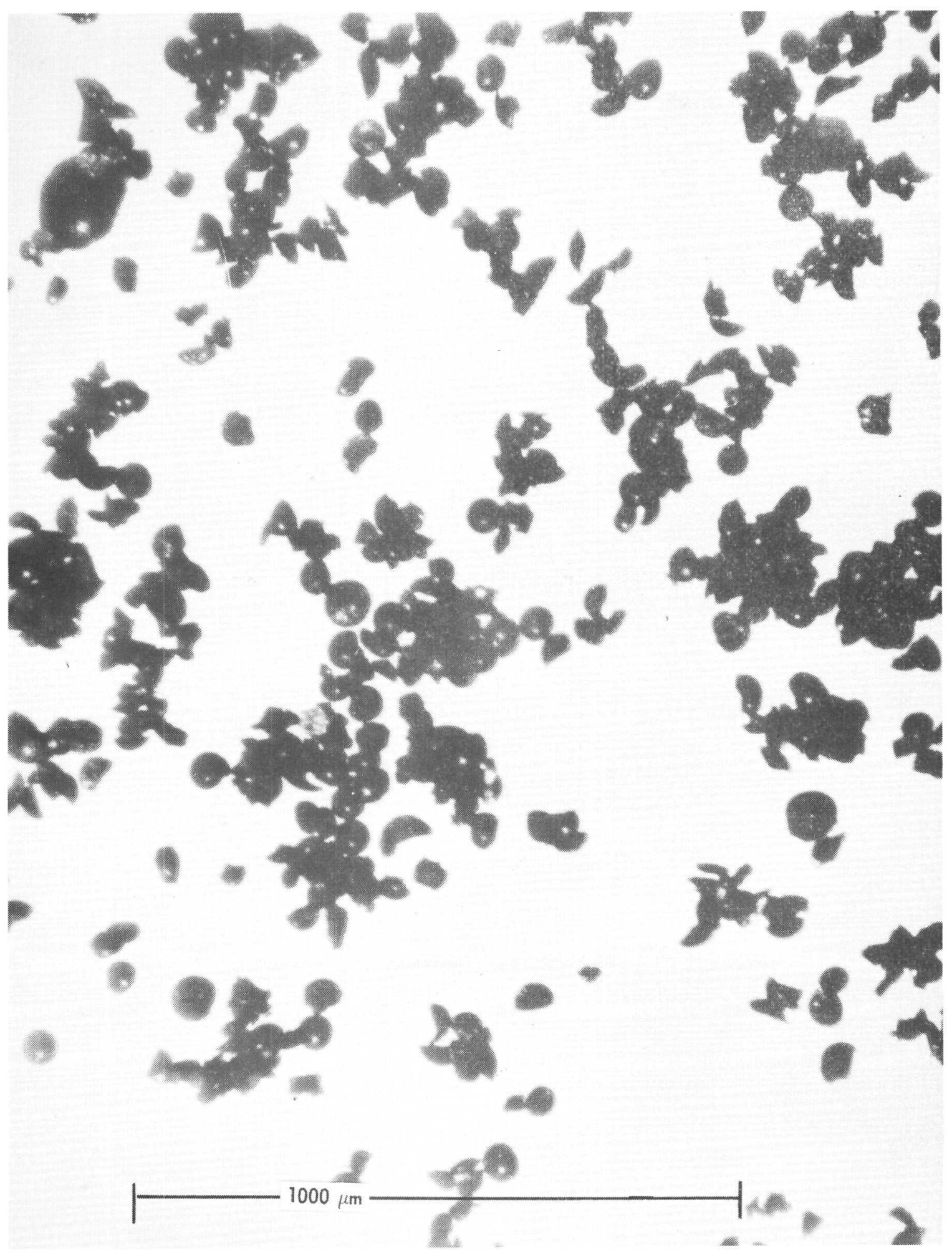

FIGURE 11 - Fines particles $(<37 \mu \mathrm{m})$ washed from fuel in liner A. 98X 


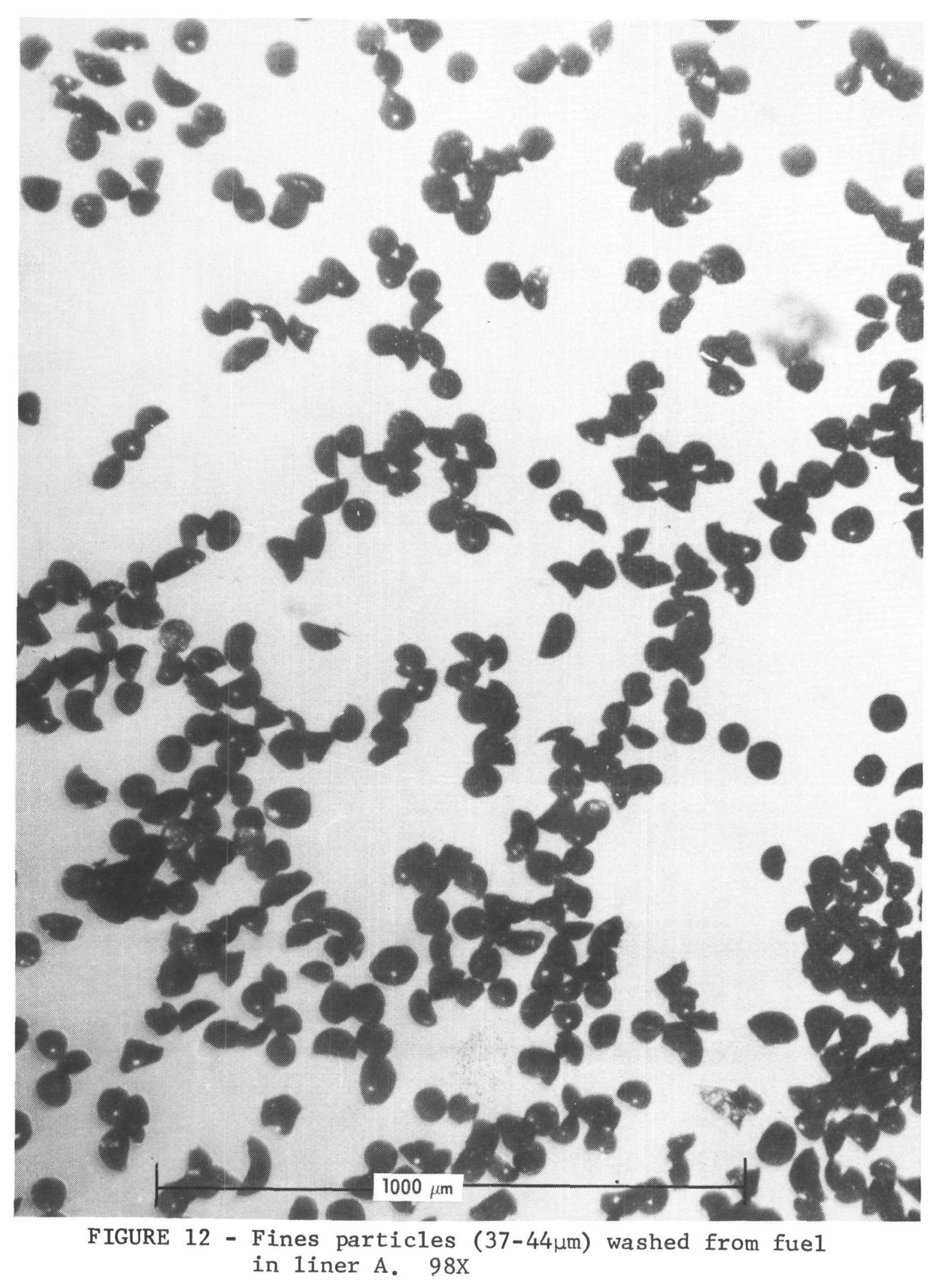




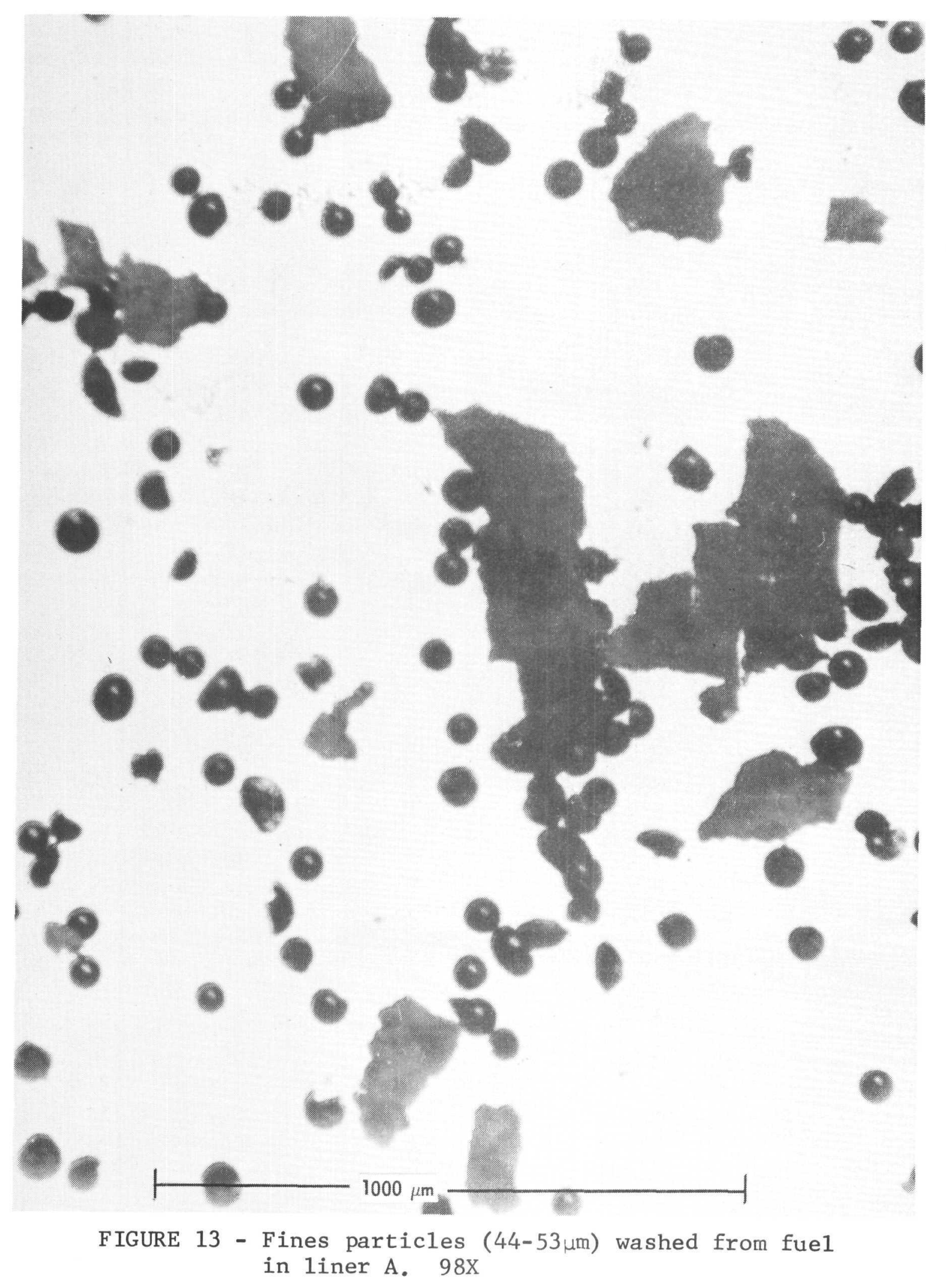


of Liner A produced 5.2-1.4 $\mathrm{g}$ or $3.8 \mathrm{~g}$ of particles with one dimension less than $53 \mathrm{\mu m}$ in size from the six batches of fuel which were washed. If this weight is added to the total weight $23.001 \mathrm{~g}$ noted above, then

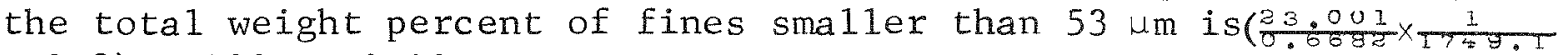
$+3.8) \times 100$ or 2.19 .

The weights of particles greater than $250 \mathrm{\mu m}$ in size are assumed to consist largely of zirconium dioxide filler because the filler size range used was nominally $300-590 \mathrm{\mu m}$, whereas the fuel was in the $50-250$ $\mu \mathrm{m}$ size range. The fuel at the top of Liner $B$ was poured into fuel container 27-4-B1 and the fuel at the bottom into 27-4-B7. The fuel from Liner A was transferred in the same manner into the containers. From the percentages of particles $>250 \mathrm{~mm}$ diameter in each batch of fuel it can be seen in the table that these particles are concentrated in the upper part of the fuel in liner $B$, whereas in Liner $A$ the particles are more evenly distributed throughout the fuel. If it is assumed that the capsule was suspended vertically by the flange through most of its 1 ife and knowing that Liner $A$ was inverted in the capsule, it can be surmised that the $>250 \mu \mathrm{m}$ particles consisting most1y of zirconium dioxide which would be at the bottom of the fuel column in Liner A would tend to migrate up through the fuel because of its lower density. However, in Liner $B$ the less dense filler which is on top of the fuel would remain near the top of the fuel column.

To replace FCA4 fuel lost during processing, batches of bonded fuel were selected. This fuel would be processed in the same manner as the FCA4 fuel before being used to load FCA8. For comparison one of the batches consisting of $253.8 \mathrm{~g}$ (isotope) of fuel was washed through the same screens as the FCA4 fuel to determine the fines distribution. The results are shown in Table 12. The total fines content amounted to $0.64 \%$ which is about one-third of that found in the FCA4 fue1. However, the size distribution is considerably different from that for the FCA4 fuel (Table 11). About $95 \%$ of the fines for the bonded fuel is in the 44-53 $\mathrm{km}$ size range. The bonded fuel after fabrication had been in storage for 15-20 months before being processed. There is some evidence that the microspheres shrink with age. This characteristic plus possible fracturing caused by additional screening could account for the high percentage of particles in the 44-53 $\mathrm{\mu m}$ range.

After completing the analysis given in row one of Table 10 for the $<37$ $\mu \mathrm{m}$ wash, the remaining washes for each batch were combined and reduced to a volume of about $50 \mathrm{ml}$ in $0.35 \mathrm{~N} \mathrm{HNO}_{3}$ solution. The solution contained about $4 \mathrm{mg}$ of plutonium as the oxide. The washes were sent to the Los Alamos Scientific Laboratory to obtain a distribution of the particle sizes less than $10 \mu \mathrm{m}$ in size.

In reducing the volume of the solution at Mound, a quantity of white particulate matter was observed to form in the solution. This condition was reported to Los Alamos. Los Alamos agreed to try to determine the distribution of particle sizes in the solution in the presence of the precipitate rather than having Mound attempt to remove the 
precipitate which might jeopardize the accuracy of the distribution data. The identity of the precipitate was not determined. At Los Alamos approximately one-half of the clear supernatent was carefully decanted off, and the remaining liquid was ultrasonically agitated to suspend the particles. A portion of the resulting slurry was spread on a clean microscope slide. The slurry was allowed to dry and the residue was used for an extraction replica. (Standard two-stage plastic/carbon replica with subsequent solution removal of the plastic leaving the residue suspended on a carbon film.) The replica was adversely affected by the presence of the unknown contaminant as seen in Figure 14 . In the figure particles of $\mathrm{PuO}_{2}$ of different sizes can be seen buried in the contaminant. The diffraction pattern in the figure shows the foreign material to be a dispersion of very fine crystallites.

Table 12

FINES ANALYSIS OF BONDED FUEL

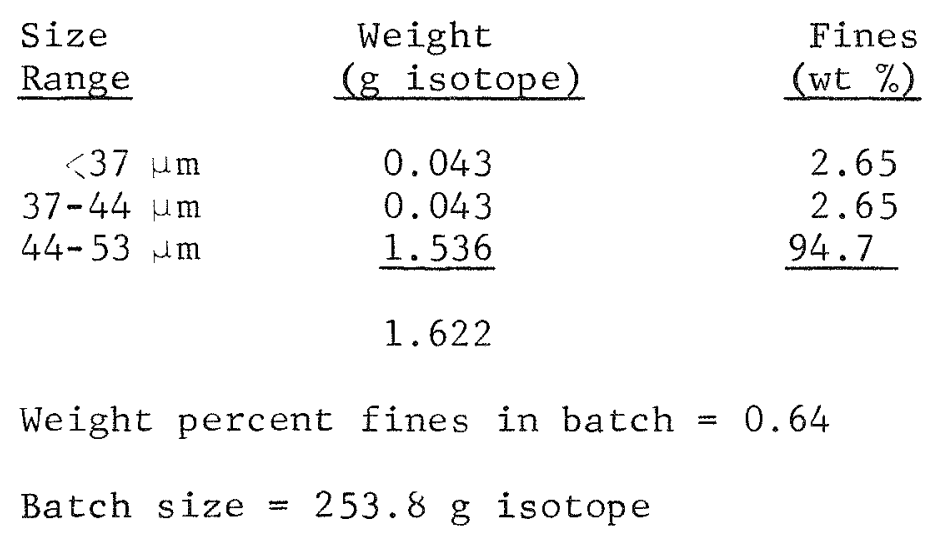

The remainder of the slurry was then diluted in water and agitated; the Puo, particles were allowed to settle; and the supernatent still containing the lighter, finer contaminant was partially withdrawn with a syringe. This separation step was repeated five times until the fines appeared to be thoroughly washed free of the contaminant. Presumably a considerable number of the smallest fines particles were lost during the separation procedure. Consequently, the weight distribution of particles in the less than $0.5 \mathrm{\mu m}$ range was adversely affected. Therefore, all particles up to $0.3 \mu \mathrm{m}$ in size were grouped together in Table 13. After the contaminant was removed from the slurry, it was possible to make replicas with good definition. Figures 15, 16, and 17 illustrate the shape and size of some of the particles. The particles were found to be $\mathrm{PuO}_{z}$ by electron diffraction. A size-weight-fraction distribution for the particles are given in Table 13. The data are plotted in Figure 16. The distribution is based on the particles in the solution recovered during the washing of $1749 \mathrm{~g}$ of $\mathrm{PuO}_{2}$ from capsule FCA4 on a $37 \mathrm{um}$ screen. 

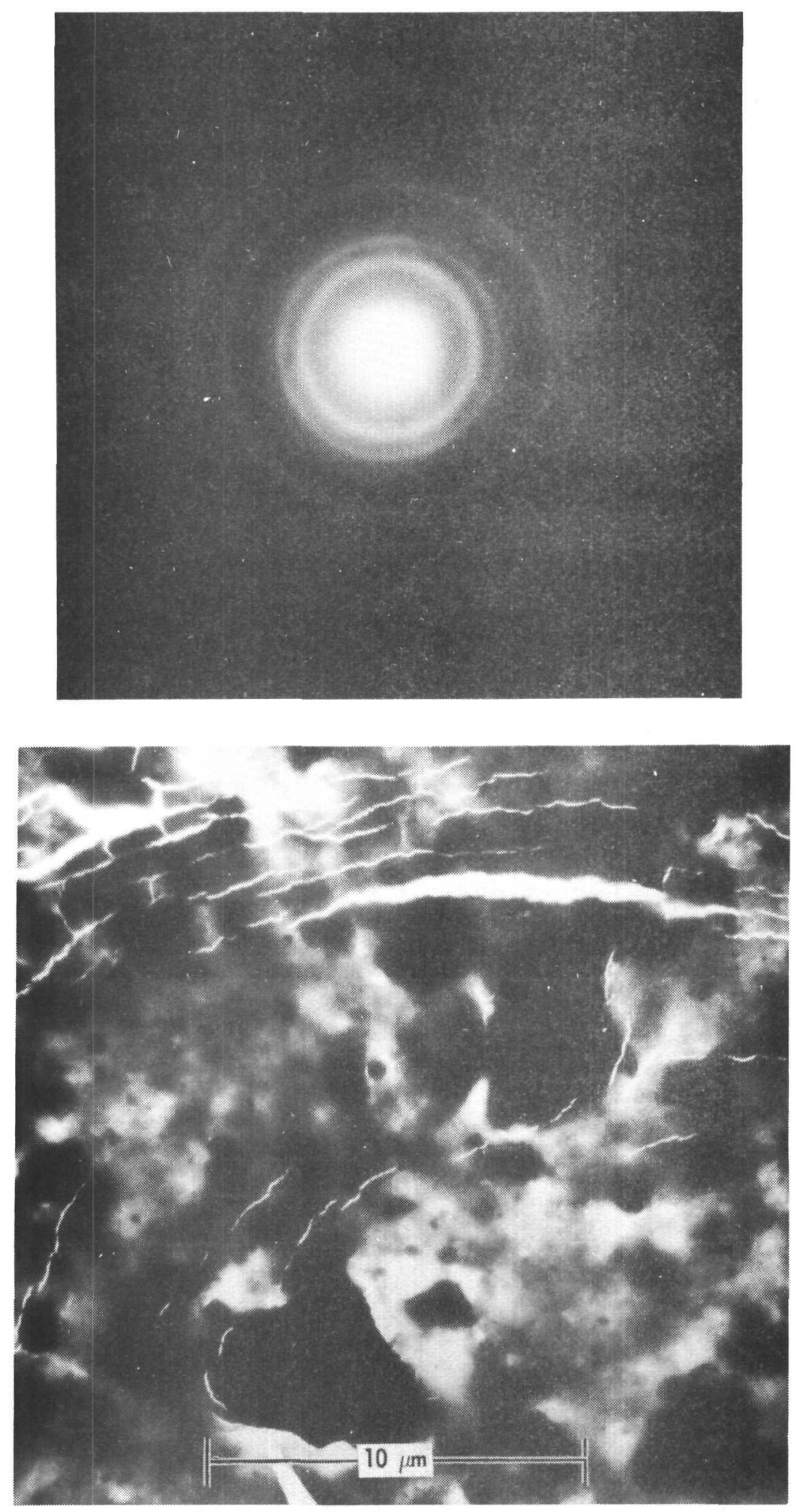

FIGURE 14 - ${ }^{3}{ }^{8} \mathrm{PuO}_{2}$ particles from FCA4 fuel imbedded in contaminant and corresponding diffraction pattern. $5000 \mathrm{X}$ 
Table 13

SIZE - WEIGHT-FRACTION DISTRIBUTION OF PARTICLES IN $<37 \mu \mathrm{m}$ WASHINGS FROM $1728 \mathrm{~g}$ OF PUO 2 REMOVED FROM SNAP-27 $\mathrm{FCA}_{4}^{\mathrm{a}}$

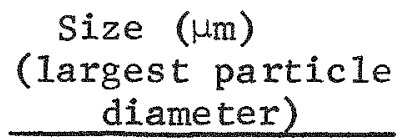

up to 0.3

110.5

10.6

110.7

110.8

" 0.9

11.0

11.25

11.5

11.75

112.0

" 2.25

112.5

$" \quad 2.75$

113.0

114.0

115.0

116.0

" 7.0

" 8.0

119.0

" $\quad 10.0$ and over
Number

422
45
29
28
27
14
11
5
13
11
14
10
5
7
7
6
17
12
8
10
17
7
$37^{\mathrm{b}}$

Weight-fraction

0.0036

0.0048

0.0061

0.0102

0.0156

0.0121

0.0135

0.0085

0.0428

0.0626

0.1266

0.1349

0.0961

0.1845

0.2455

0.2732

1.8351

2.5306

2.9145

5.7852

14.6805

8.6069

62.4056

a Both the low statistics and probable experimental 1oss of particles less than $0.3 \mathrm{~mm}$ make this distribution suspect.

b Nine of these particles had all dimensions over $10 \mu \mathrm{m}$. 
FIGURE 15 - 2 з $8 \mathrm{PuO}_{2}$ particles taken from FCA4 fuel together with confirming diffraction pattern of large particle on the left.
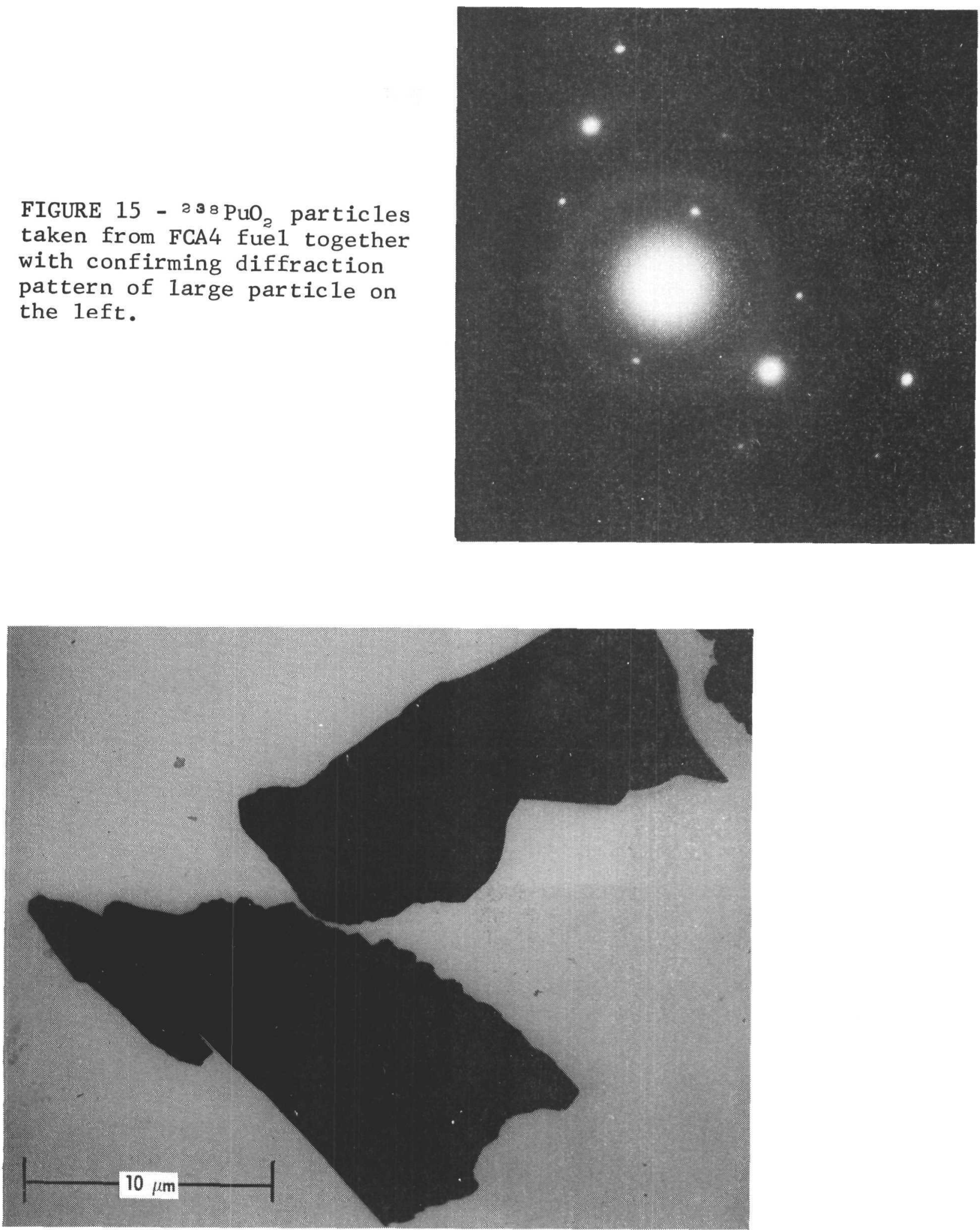

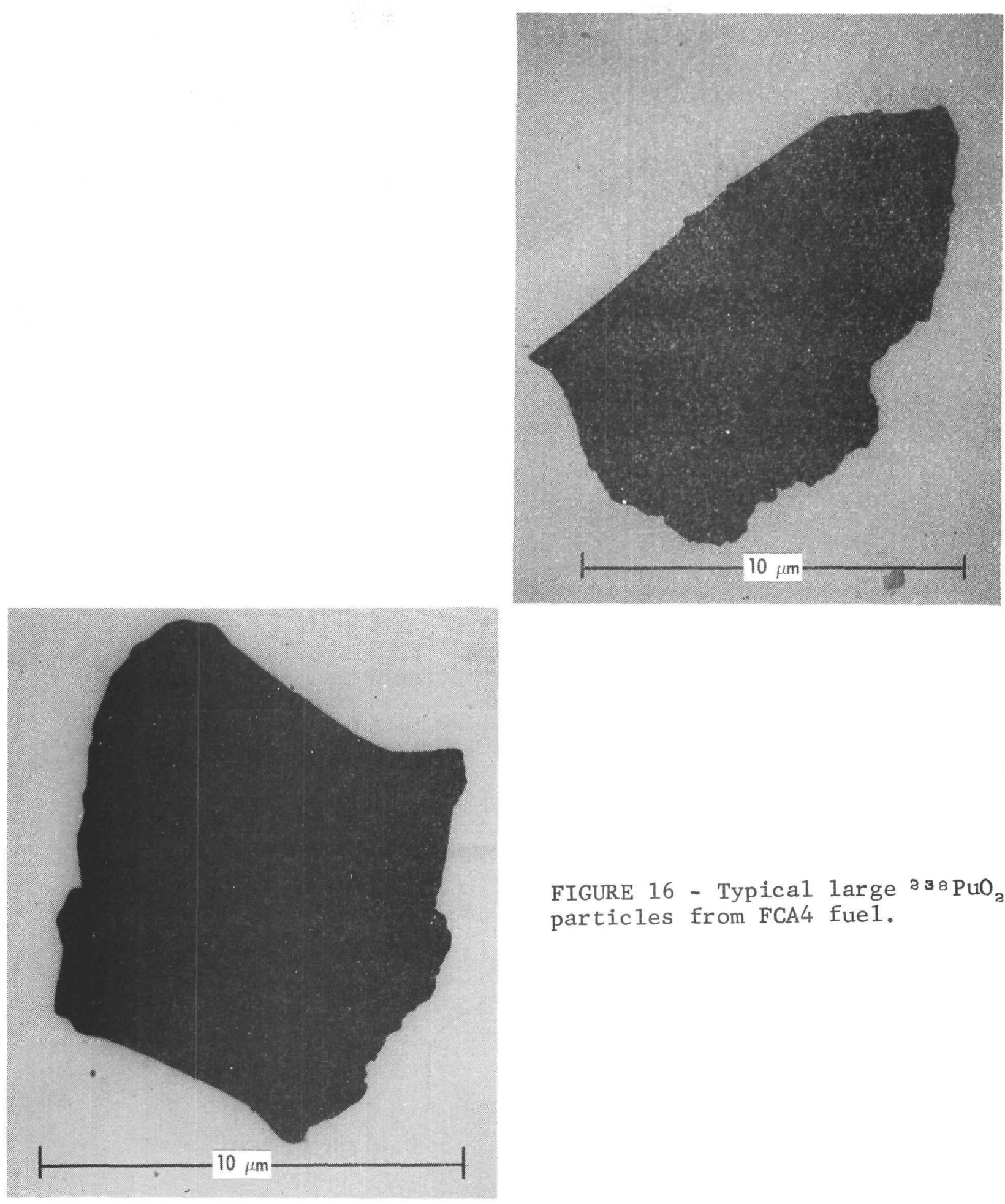

FIGURE 16 - Typical large азв $\mathrm{PuO}_{2}$ particles from FCA4 fuel. 

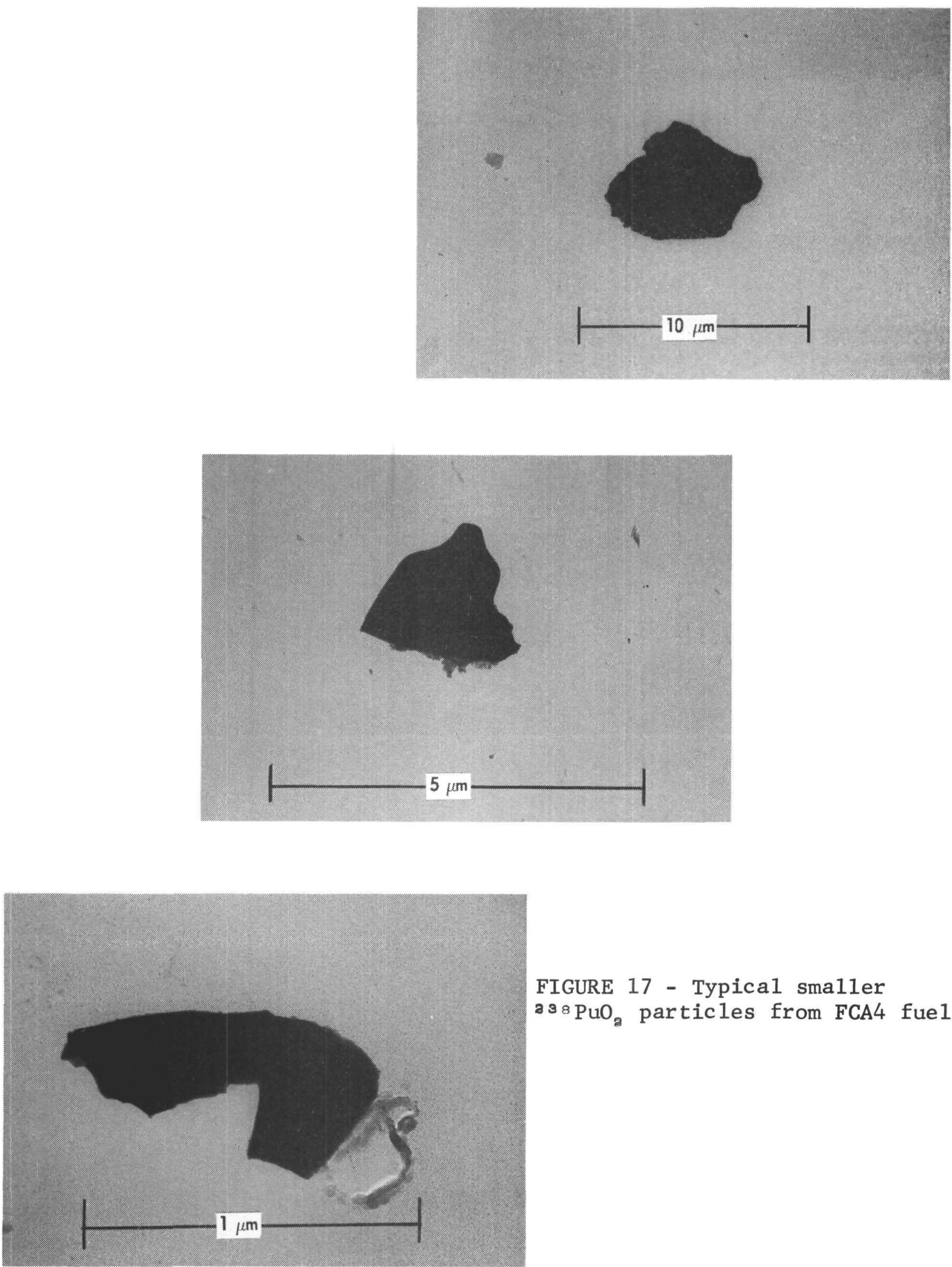

FIGURE 17 - Typica1 sma11er

3 з $\mathrm{PuO}_{2}$ particles from FCA4 fuel. 


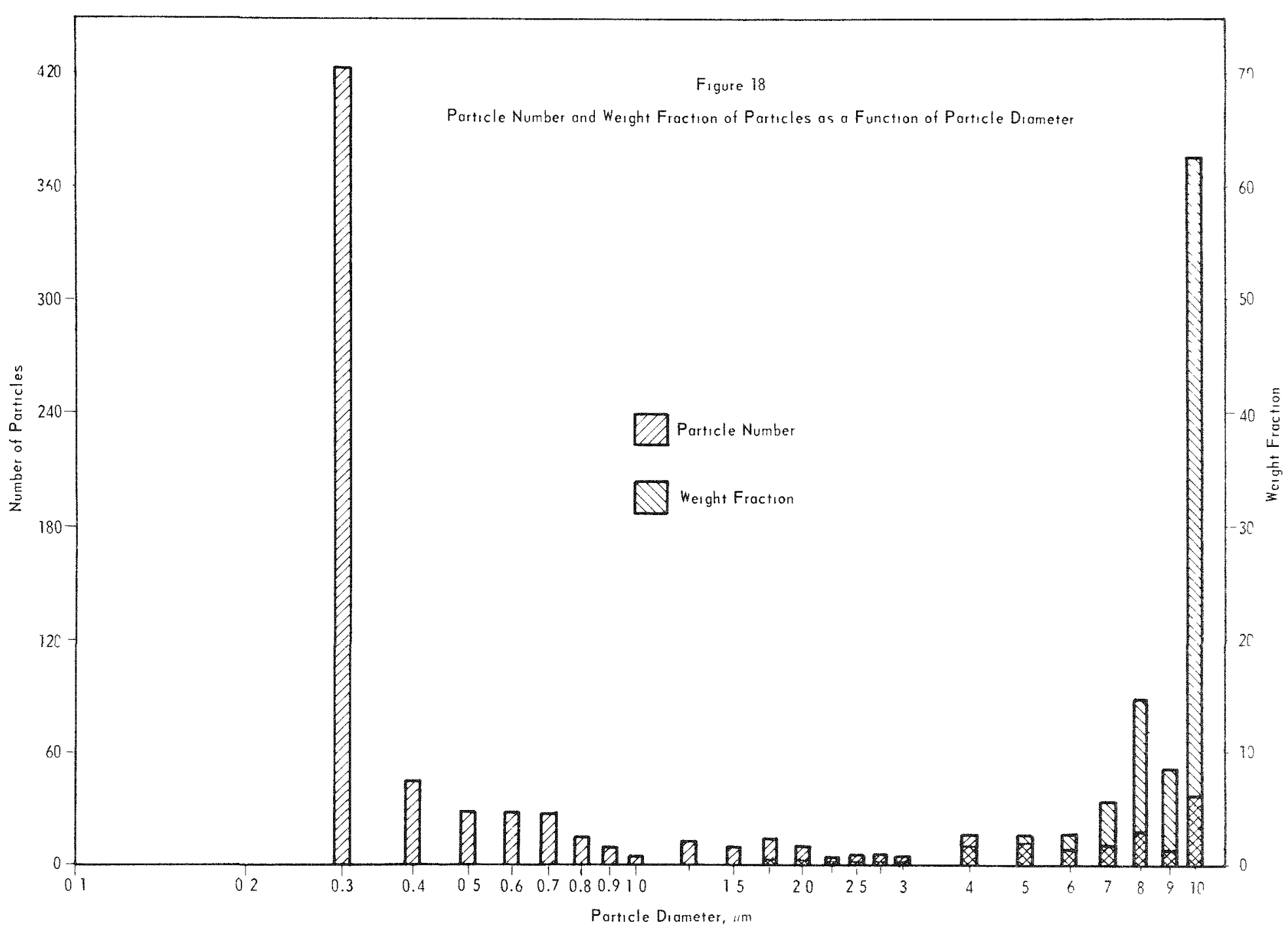
function of particle diameter. 
4. Helium Removal Studies Before the fuel form FCA4 was used to load FCA8, it was necessary to remove the bulk of the entrapped helium from the fue1. This step was necessary to comply with the requirement that the fuel contain no more helium than would be produced by the decay of the fuel over a six-month period. The method chosen to remove the helium was to bake the fuel in air at an elevated temperature. To determine whether the fuel would be adversely affected by the baking procedure, a sample of fuel from a SNAP-19 capsule was used for this study. The test sample would also demonstrate whether baking the fuel in air would remove the helium sufficiently. Previously, bakeout tests at Mound had been performed in vacuum.

The sample was obtained from SNAP-19 capsule $\# 369 / 375$, batch 2, and was screened to retain the 50 to $250 \mathrm{\mu m}$ fraction. The $23-\mathrm{g}$ sample was washed on a $50 \mathrm{\mu m}$ screen with $250 \mathrm{ml}$ of wash solution. The solution. was discarded. The sample was again washed with $250 \mathrm{ml}$ of solution which was retained for fines determination.

The sample was divided into three $6-g$ samples for the bakeout study and into two $2-\mathrm{g}$ analytical samples. The stoichiometry, size, shape, density, fines content, and cation impurities of the fuel were determined from the analytical samples. The before bakeout data are reported in Table 14. Portions of the $6-\mathrm{g}$ samples after being baked out were also taken and analyzed for the same attributes to determine what effects the baking out had on these characteristics.

The three bakeout samples each containing $5.7 \mathrm{~g}$ of fuel as oxide were identified as 19-27-1, 19-27-2, and 19-27-3. The first two were used for the air bakeout studies and the third one was used for vacuum bakeout. The vacuum sample was used in two ways. One portion was used to determine the total helium content retained by the sample, and another portion was treated in the same manner as the two air samples.

Previous work ${ }^{3}$ had demonstrated that vacuum bakeout involving fast thermal excursions to $1300^{\circ} \mathrm{C}$ effectively reduced the helium inventory of microspheres in $20 \mathrm{~min}$ at maximum temperature. However, the bakeout time and temperature for adequately reducing the helium content of microspheres baked in air was not known. Therefore, it was decided to bake both air samples at $1300^{\circ} \mathrm{C}$ with one being held for $1 \mathrm{hr}$ and the other for $2 \mathrm{hr}$ at temperature. Portions of these samples then would be baked in vacuum to remove any helium remaining to check the effectiveness of the air bakeout method.

The studies were initiated by taking $0.251 \mathrm{~g}$ of the vacuum sample 19-27-3 to determine the helium inventory for all three samples. The sample was placed in the helium release experimental setup and heated to approximate $1 \mathrm{y} 1300^{\circ} \mathrm{C}$ in vacuum in less than $6 \mathrm{~min}$. The sample was

${ }^{3} \mathrm{P}$. Angelini, et a1., Helium Release from ${ }^{238} \mathrm{PuO}_{2}$ Microspheres, ORNL4507, Oak Ridge National Laboratory (March 1970). 
Table 14

\section{ANALYSTS OF SNAP- 19 FUEL SAMPLES \\ FROM BAKEOUT TESTS}

\begin{tabular}{|c|c|c|c|c|}
\hline \multirow{2}{*}{$\begin{array}{c}\text { Cation } \\
\text { Impurities }\end{array}$} & $\begin{array}{l}\text { Anount } \\
\text { Before }\end{array}$ & Amoum & E Bakeout & \\
\hline & $\begin{array}{l}\text { Bakeout } \\
\text { (ppm) }\end{array}$ & I hrair & $2 h r$ a ir & vacuum \\
\hline A 1 & 100 & 50 & 50 & 200 \\
\hline $\mathrm{Ba}$ & 150 & $<50$ & ND & ND \\
\hline $\mathrm{Ca}$ & 350 & $<250$ & 250 & 250 \\
\hline Co & ND & $\mathrm{ND}$ & ND & ND \\
\hline $\mathrm{Cr}$ & 400 & 50 & 600 & 130 \\
\hline $\mathrm{Cu}$ & 50 & 50 & $<50$ & 50 \\
\hline $\mathrm{Fe}$ & 600 & $>1000$ & -1000 & $>1000$ \\
\hline & & $<3000$ & & \\
\hline $\mathrm{Mg}$ & 80 & $<50$ & 50 & 70 \\
\hline $\mathrm{Mn}$ & $<50$ & 50 & $<50$ & $<50$ \\
\hline $\mathrm{Na}$ & ND & ND & $\mathrm{ND}$ & ND \\
\hline $\mathrm{Ni}$ & 250 & $<\quad 50$ & 50 & $<50$ \\
\hline $\mathrm{Si}$ & 750 & 900 & $>1000$ & $>1000$ \\
\hline $\mathrm{Zn}$ & ND & ND & 50 & 50 \\
\hline Total ppm & 2780 & 5500 & 3150 & 2850 \\
\hline Total Percent & 0.28 & 0.55 & 0.32 & 0.29 \\
\hline Stoichiometry & -- & $\mathrm{PuO}_{2}$ & $\mathrm{PuO}_{2}$ & $\mathrm{PuO}_{2}$ \\
\hline Size \& Shape & OK & OK & OK & OK \\
\hline App. Density & /cc) 9.71 & - & 10.6 & 10.2 \\
\hline Lattice $\mathbf{A}$ & 5.3974 & 5.4095 & 5.4119 & 5.4069 \\
\hline Fines $(w t \%)$ & $1.8 \times 10^{-3}$ & $7.0 \times 10$ & $6.5 \times 10^{-3}$ & $3.3 \times 10$ \\
\hline
\end{tabular}


maintained at this temperature until a decrease in the helium release rate was noted, then further heated to approximately $1950^{\circ} \mathrm{C}$ to drive out any residual helium that could have been retained in the sample. The sample was cooled and taken off test when the helium release rate had decreased to the background rate of the measuring equipment. The results of this experiment are shown in Table 15.

Table 15

VOLUME OF HELIUM REMOVED BY BAKEOUT

IN AIR AND VACUUM AT $1300^{\circ} \mathrm{C}$

\begin{tabular}{llc} 
Sample & $\begin{array}{l}\text { Helium } \\
\text { Removed } \\
(\mathrm{cc} / \mathrm{g})\end{array}$ & $\begin{array}{c}\text { Helium } \\
\text { Removed } \\
(\%)\end{array}$ \\
\cline { 2 - 3 } $19-27-1$ & 0.1231 & 83 \\
$19-27-2$ & 0.1462 & 98.5 \\
$19-27-3$ & 0.1484 & 100
\end{tabular}

The remaining $5.449 \mathrm{~g}$ of sample were heated in a vacuum furnace using the following thermal profile: 5 min from ambient temperature to $1300^{\circ} \mathrm{C} ; 20$ min at $1300^{\circ} \mathrm{C}$; manual cool down to ambient temperature. The sample was then analyzed for the various attributes noted above. The results are reported under the vacuum column in Table 14.

Next the entire 19-27-1 sample was baked out in air. First the furnace was allowed to heat to and stabilize at $700^{\circ} \mathrm{C}$. The sample in a highfired $\mathrm{Al}_{2} \mathrm{O}_{3}$ crucible was placed in the furnace and the furnace temperature was increased to $1300^{\circ} \mathrm{C}$ in $45 \mathrm{~min}$. The furnace was maintained at $1300^{\circ} \mathrm{C}$ for $1 \mathrm{hr}$. The sample was then removed and allowed to air-cool.

Approximately $0.533 \mathrm{~g}$ of this sample was later heated in vacuum at $1950^{\circ} \mathrm{C}$ to determine the amount of helium removed. The results are shown in Table 15. The balance of the sample was washed and analyzed. The results are listed in the column 1-hr air in Table 14.

Now the 19-27-2 sample was baked out in the same manner as sample 19-27-1 with the exception that this sample was removed from the furnace after 2 hr at $1300^{\circ} \mathrm{C}$ and air-cooled.

Approximately $0.185 \mathrm{~g}$ of this sample was used to determine the helium removed while the remaining portion was washed and used for analysis. The data are given in the colum 2-hr air in Table 14. The amount of helium baked out is shown in Table 15 .

The volumes are corrected for the time between bakeout at $1300^{\circ} \mathrm{C}$ and the residual helium determination. It was assumed that all the helium generated during this interval ( 6.5 days) was retained by the fuel. 
At the time that the samples were taken the tuel had been in FCA4 about $2.25 \mathrm{yr}$. If the fuel had accumulated a six-month inventory of helium prior to being placed in the capsule then the fuel would have a total helium inventory of 2.75 yr assuming that all the helium was entrapped in the fuel. Calculations using the factor $1.67 \times 10^{-8} \mathrm{cc} \mathrm{He} / \mathrm{g} / \mathrm{sec}$, which is the generation rate for helium in microspheres, showed that $1.459 \mathrm{cc} \mathrm{He} / \mathrm{g}$ would accumulate in $2.75 \mathrm{yr}$. If a 2 -hr air bakeout reduces the helium to $1.45 \%$ of the original amount, then only $0.0211 \mathrm{cc}$ $\mathrm{He} / \mathrm{g}$ would remain which is equivalent to the helium generated in $1 \mathrm{~g}$ of microspheres in about 15 days. This value is well below the maximum helium inventory of six months allowed in the fuel at time of encapsulation. Of course, the release data were obtained from 5-g samples. If the bakeout parameters are as effective in treating large quantities of fuel, then the bakeout at $1300^{\circ} \mathrm{C}$ in air for $2 \mathrm{hr}$ should remove an adequate quantity of helium to qualify the fuel for encapsulation in FCA8.

A review of the data in Table 14 shows that the attributes of the fuel were not significant1y changed by the bakeout procedure. There was some increase in the iron impurity which may have been introduced during the baking. Nevertheless, the total cation impurity content of the samples were, as a maximum, about $0.5 \%$ which is appreciably less than the $2 \%$ maximum allowed for the fuel. The fines content for the samples after bakeout were higher. However, such additional fines as may be formed by baking can be removed by additional washing of the fuel.

With the conclusion of the bakeout study the removal of the helium from the FCA4 fuel was begun. A composite sample of the fuel from Liner A was analyzed to determine its characteristics before bakeout. The data are given in Table 16. The table also includes the original analysis of the fuel when it was placed in FCA4 some two years ago. The size of the fuel batches baked out were 400-600 g oxide. A11 batches were held at $1300^{\circ} \mathrm{C}$ in air. The first two of the 10 batches were heated for $4 \mathrm{hr}$, the others for $6 \mathrm{hr}$.

To determine whether the bakeout parameters were as effective in removing helium from large batches of fuel as from small ones, representative samples were taken from three of the heated batches and tested to obtain the residual helium value. For the test $0.25-\mathrm{g}$ samples were held at $2000^{\circ} \mathrm{C}$ in vacuum. The amount of helium in each sample in terms of days required to generate the volume of helium found was 13, 66, and 24 days. Because the accuracy of the test method was estimated to be \pm 20 days, the above values appear to agree with each other within the limits of experimental error. The results indicate that the bakeout parameters are effective in removing the helium from the fuel. They also show that the residual helium is well below the maximum allowable limit of 180 days.

A sample from one of the batches was analyzed to determine the fuel characteristics after bakeout. The values are given in the last column of Table 16 . 
Table 16

ANALYSIS OF SNAP-27 FCA4 FUEL

BEFORE AND AFTER BAKEOUT

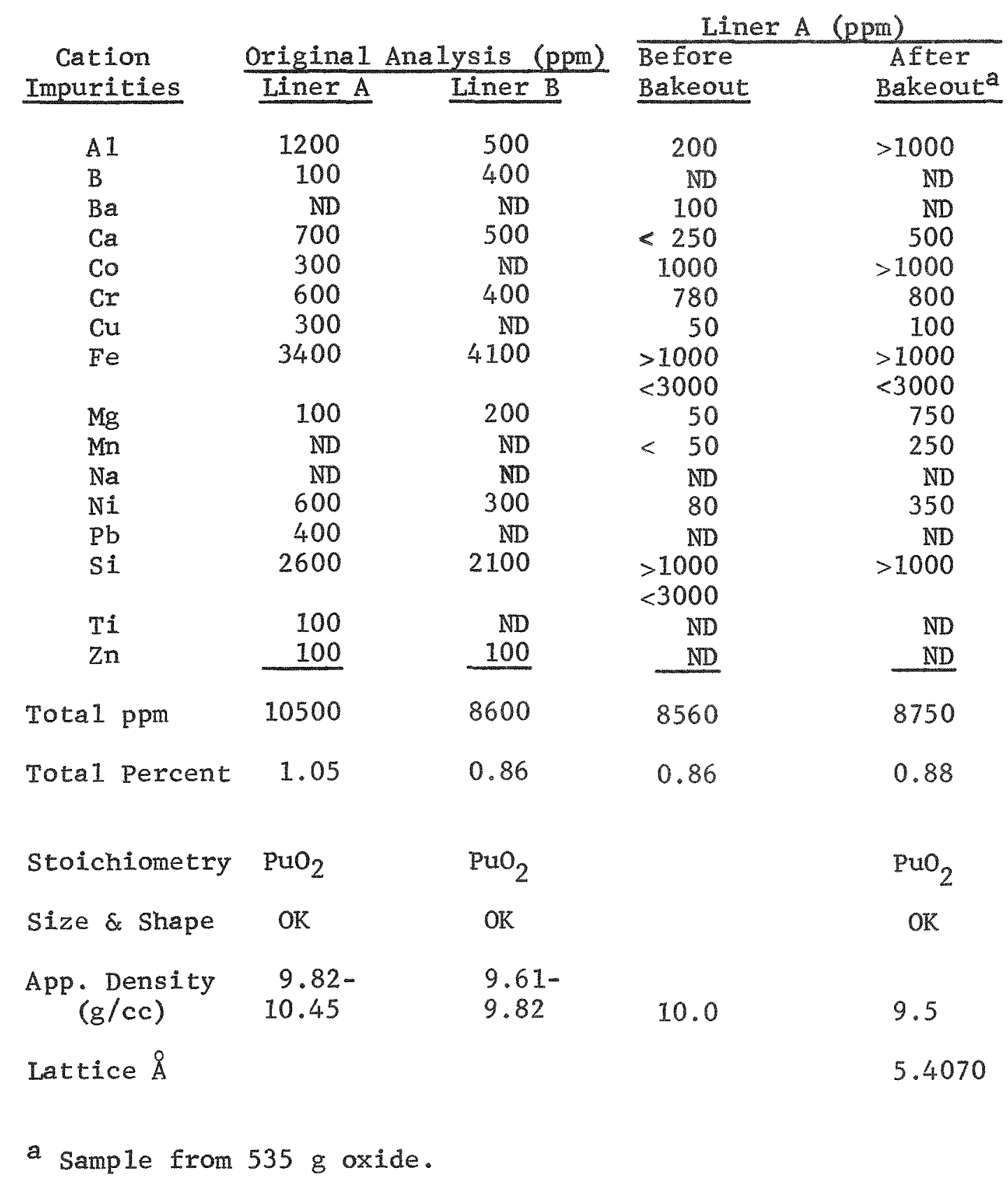


Following the bakeout work the fuel was screened, segregated, and washed to comply with the SNAP-27 fuel specifications. The fuel was assembled into batches for calorimetry, and the thermal power was measured in preparation for loading the fue 1 in FCA8. To replace FCA4 fue1 lost during processing sufficient fuel was removed from bonded storage and added to that of FCA4 to provide the required amount of fuel for FCA-8. The bonded fuel was a1so baked out, screened, segregated, washed, and calorimetered. The characteristics of the fuel prepared for FCA8 are given in Table 17.

In processing the fue 1 for FCA8, including the bonded fuel, the amount of fuel which could not be accounted for amounted to only $30.5 \mathrm{~g}$ (isotope) out of a total weight of $3726.3 \mathrm{~g}$ (isotope) handled. The percent loss then is 0.82 . As the calorimetric method used for determining the quantities of fuel is estimated to have an accuracy of $\pm 0.6 \%$ then the real loss could be even less than the $30.5 \mathrm{~g}$ indicated. The low loss attests to the careful handing practiced during the processing of the fuel.

Finally the amount of fuel from FCA4 which remained after al1 the processing and which qualified for use in FCA8 was $1176.11 \mathrm{~W}$ (th) as of March 1971.

\section{ACKNOWLEDGEMENTS}

The examination of SNAP-27 FCA4 and preparation of the fuel for FCA8 at Mound Laboratory required the close cooperation of several disciplines. In particular, personnel of the Applications Technology, Plutonium Processing, and Quality and Reliability sections of the Nuclear Operations Department deserve acknowledgement. Appreciation is extended to the gaging section and engineering groups at Mound Laboratory and to the various personnel in the Atomic Energy Commission for their assistance and encouragement. 
Table 17

ANALYSIS OF SNAP- 27 FCA4 FUEL USED IN FCA8

Cation Impurities

$\mathrm{Ag}$
$\mathrm{Al}$
$\mathrm{B}$
$\mathrm{Ba}$
$\mathrm{Be}$
$\mathrm{Ca}$
$\mathrm{Co}$
$\mathrm{Cr}$
$\mathrm{Cu}$
$\mathrm{Fe}$
$\mathrm{Mg}$
$\mathrm{Mn}$
$\mathrm{Na}$
$\mathrm{Ni}$
$\mathrm{Pb}$
$\mathrm{Si}$
$\mathrm{Ti}$
$\mathrm{Zn}$

Tota1 ppm

Total percent

Size \& Shape

App. Density ( $/ / c c)$

Fines (wt \%)
Ana 1ysis (ppm)

\begin{tabular}{|c|c|c|}
\hline Lot A & Lot B & Lot C \\
\hline$\ll 50$ & ND & ND \\
\hline 400 & 50 & 50 \\
\hline ND & $\mathrm{ND}$ & $\mathrm{ND}$ \\
\hline 70 & $<50$ & $\mathrm{ND}$ \\
\hline$\ll 50$ & ND & $\mathrm{ND}$ \\
\hline 440 & $<250$ & $<250$ \\
\hline 1000 & $\mathrm{ND}$ & $\mathrm{ND}$ \\
\hline 340 & 100 & 150 \\
\hline 50 & 50 & $<50$ \\
\hline$>1000$ & 950 & 690 \\
\hline \multicolumn{3}{|l|}{$<3000$} \\
\hline 250 & 50 & 50 \\
\hline 100 & 50 & 50 \\
\hline $\mathrm{ND}$ & ND & $\mathrm{ND}$ \\
\hline 170 & 80 & 50 \\
\hline$<\quad 50$ & $\mathrm{ND}$ & ND \\
\hline$>1000$ & 500 & 50 \\
\hline \multicolumn{3}{|l|}{$<3000$} \\
\hline 500 & ND & $\mathrm{ND}$ \\
\hline $\mathrm{ND}$ & ND & 180 \\
\hline 9470 & 2130 & 1570 \\
\hline 0.95 & 0.21 & 0.16 \\
\hline OK & OK & OK \\
\hline
\end{tabular}

$\begin{array}{lll}9.6 & 9.5 & 10.3\end{array}$

$5.0 \times 10^{-4} \quad 6.9 \times 10^{-5}$

$2.8 \times 10^{-4}$

$5.0 \times 10^{-5}$

$5.2 \times 10^{-4}$

$5.7 \times 10^{-4}$

$3.8 \times 10^{-5}$

$8.9 \times 10^{-5}$ 


\section{APPENDIX A \\ OPERATION OF HELIUM RELEASE MEASURING APPARATUS \\ (FIGURE 7)}

I. Check-out of Vacuum System
A. Close valves 5, 9, and 13 - a11 other valves are open.
B. Balance MKS sensor.
C. Close valve 3 and main valve 1 and determine leak rate of system.
D. Repeat step $\mathrm{C}$ with dri11 rotating.
E. When satisfactory leak rate has been obtained, close valves 6 and 7.

II. Determine Volume of System

F. Pressurize system to 10-20 torr by opening valve 5. Record stabilized pressure $\mathrm{P}_{1}$.

G. Open standard volume valve 6 . Record stabilized pressure $P_{2}$.

H. Calculate system volume $V_{1}$

$$
\frac{\mathrm{P}_{1}}{\mathrm{P}_{2}}=\frac{\mathrm{V}_{1}+\mathrm{V}_{\text {std }}}{\mathrm{V}_{1}}
$$

III. Helium Measurement

I. Close valve 5. All other valves are open to the vacuum pumping system.

J. Balance MKS sensor.

K. Close valves $3,6,9$, and the main valve 1 .

L. Drill open capsule. After opening, locate the drill shaft at the same position used in standardizing the system volume.

M. Record the stabilized pressure $\mathrm{P}_{3}$ (mm Hg).

N. Calculate volume of gas in capsule $V g=\frac{P_{3}}{760} V$

This assumes the temperature to be uniform within the system. For a capsule the size of the SNAP-27 this is not true and some error will be introduced by this method. 